\title{
Mathematics of the Armington, Krugman and Melitz Models with Multiple Sectors and Heterogeneous Regions, with Detailed Derivations
}

\author{
Edward J. Balistreri, David G. Tarr \\ Working Paper 19-WP 596 \\ November 2019 \\ Center for Agricultural and Rural Development \\ lowa State University \\ Ames, lowa 50011-1070 \\ www.card.iastate.edu
}

Edward J. Balistreri is Associate Proffessor, Department of Economics, lowa State University, Ames, IA 50010. E-mail: ebalistr@iastate.edu.

David G. Tarr is former Lead Economist, The World Bank, Miami, FL 33101. E-mail: dgtarr@gmail.com.

This publication is available online on the CARD website: www.card.iastate.edu. Permission is granted to reproduce this information with appropriate attribution to the author and the Center for Agricultural and Rural Development, lowa State University, Ames, lowa 50011-1070.

For questions or comments about the contents of this paper, please contact Edward J. Balistreri, ebalistr@iastate.edu

\footnotetext{
lowa State University does not discriminate on the basis of race, color, age, ethnicity, religion, national origin, pregnancy, sexual orientation, gender identity, genetic information, sex, marital status, disability, or status as a U.S.

veteran. Inquiries regarding non-discrimination policies may be directed to Office of Equal Opportunity, 3410

Beardshear Hall, 515 Morrill Road, Ames, lowa 50011, Tel. (515) 294-7612, Hotline: (515) 294-1222, email

eooffice@iastate.edu.
} 


\title{
Mathematics of the Armington, Krugman and Melitz Models with Multiple Sectors and Heterogeneous Regions, with Detailed Derivations
}

\author{
Edward J. Balistreri, Associate Professor, Iowa State University and \\ David G. Tarr, Former Lead Economist, The World Bank
}

November 20, 2019

\begin{abstract}
In Balistreri and Tarr (2018), we numerically assess the relative welfare impacts of trade cost reductions in models based on Armington (1969), Krugman (1980) and Melitz (2003). In order to be able to apply these models to data, Balistreri and Tarr (2018) consider extended or general versions of these models to include: intermediates with data-based shares of inputs, labor-leisure choice, heterogeneous regions based on data, initial heterogeneous tariffs as well as iceberg costs, multiple factors of production and the possibility of sector-specific inputs. In this paper we provide detailed derivations of the equilibrium conditions of these models. We hope these derivations will be a clear roadmap for understanding and constructing modern multi-sector, multi-region international trade models that must be fitted to data.
\end{abstract}

Keywords: heterogeneous firms; heterogeneous regions; gains from the new trade theory; labor-leisure choice.

JEL classification: F12; F13; C65; C68; D58

* We thank Thomas Rutherford, Avinash Dixit, Jonathan Dingel, Maryla Maliszewska, Russell Hillberry, Aaditya Mattoo and Will Martin for comments. The authors gratefully acknowledge support from the World Bank Research Committee under grant RF-P159745-RESE-BBRSB. Balistreri also acknowledges base support from the USDA National Institute of Food and Agriculture (NIFA) Hatch Project [grant number 1010309]. The views expressed are those of the authors and do not necessarily reflect those of the World Bank, its Executive Directors or those acknowledged. 


\section{Table of Contents}

Mathematics of the Armington, Krugman and Melitz Models with Multiple Sectors and Heterogeneous

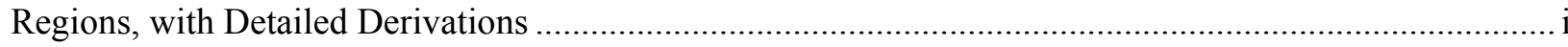

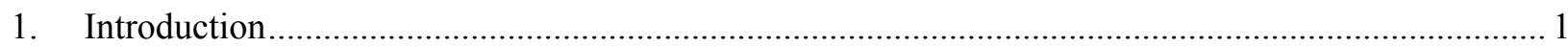

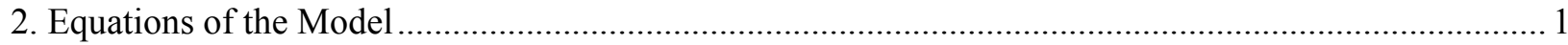

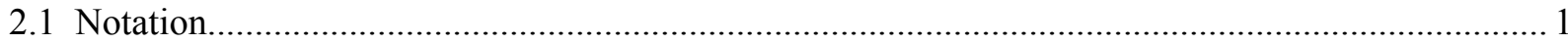

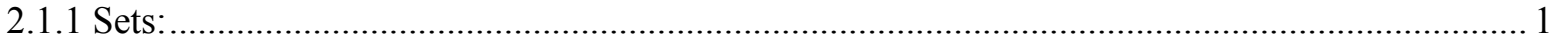

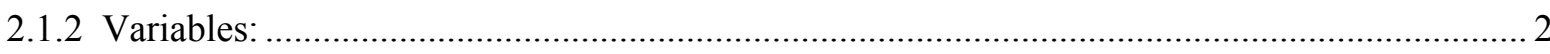

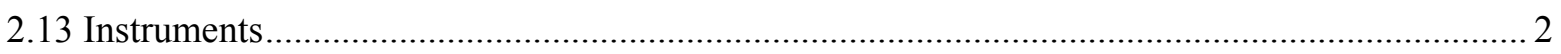

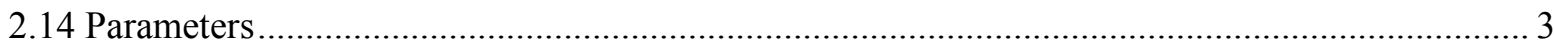

2.2 Representing technologies and preferences using duality .................................................... 4

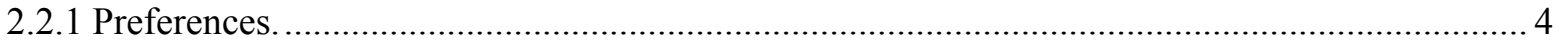

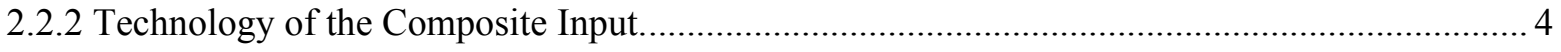

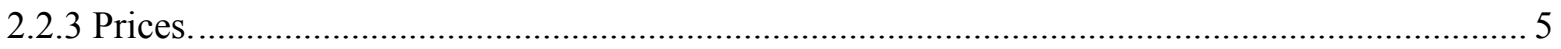

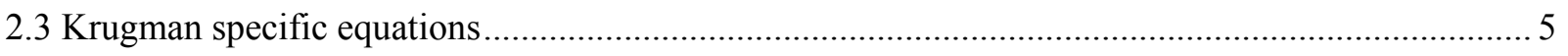

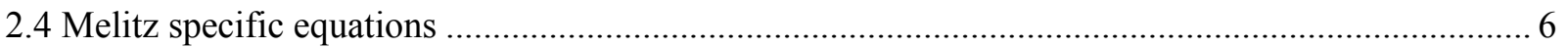

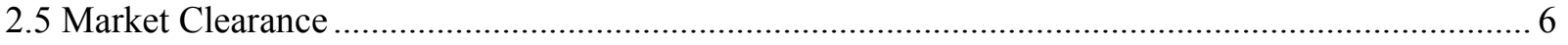

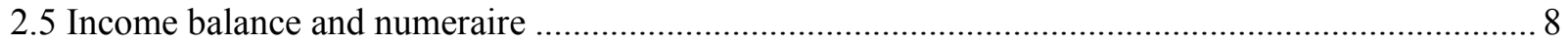

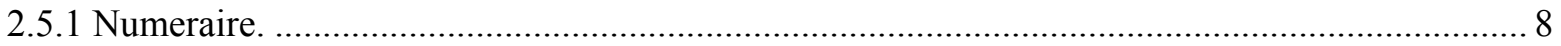

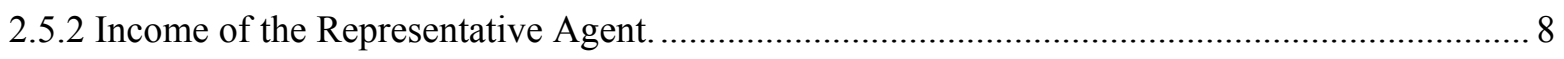

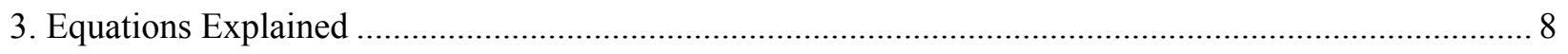

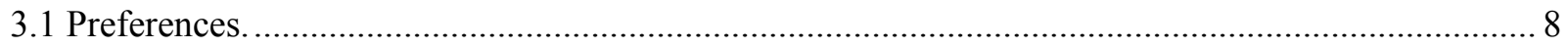

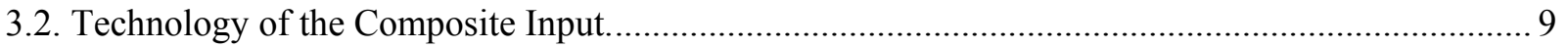

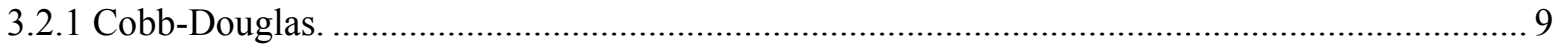

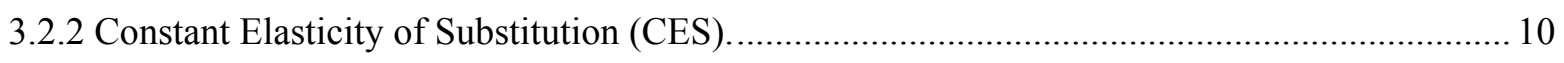

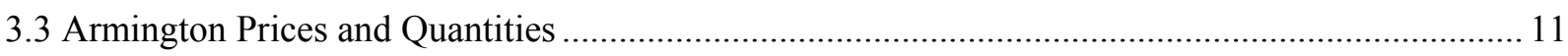

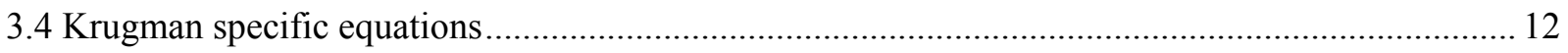

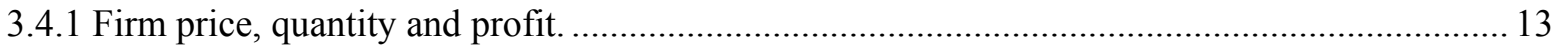

3.4.2 Free Entry Condition................................................................................................ 15

3.4.3 Preference Weights in the Dixit-Stiglitz Price Equation of the Krugman model. ................... 16

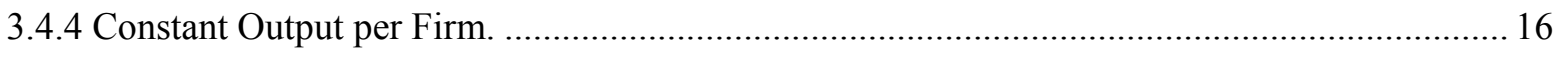

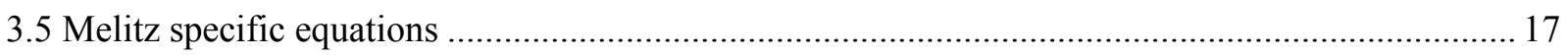

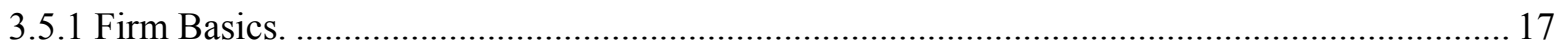

3.5.2 Firm Level Prices, Quantity, Profits and Revenue................................................................... 18 
3.5.3 Aggregate and Representative Firm Variables. ................................................................. 22

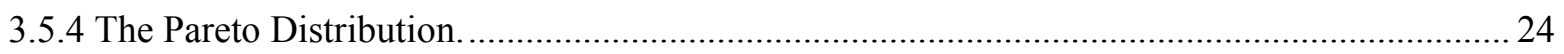

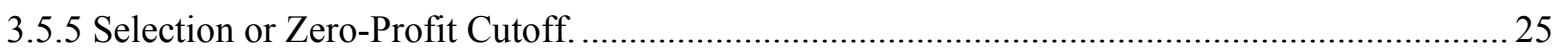

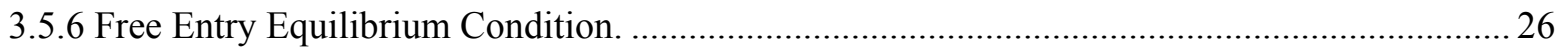

3.5.7 Representative Firm Productivity Level. ............................................................................. 27

3.5.8 Preference Weights in the Dixit-Stiglitz Price Equation of the Melitz Model......................... 27

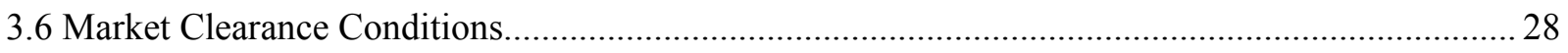

3.6.1 Supply and Demand Balance for Domestic Use..................................................................... 28

3.6.2 Market Clearance of Good $i$ in Region $r$ in all uses for Armington Goods. ............................ 28

3.6.3 Market Clearance of Good $\mathrm{k}$ in Region $\mathrm{r}$ in all uses for Krugman Goods...............................29

3.6.4 Market Clearance of Good $m$ in Region $r$ in all uses for Melitz Goods. ................................29

3.6.5 Market Clearance for sector-specific primary factors.......................................................... 30

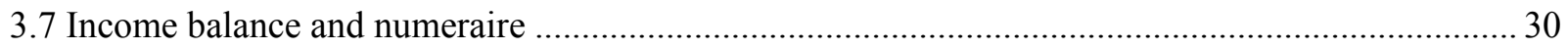

3.8 Hicksian Equivalent Variation and its Equivalence to the Change in Real Income ........................ 31

3.8.1 No Labor-Leisure Choice Case ......................................................................................... 31

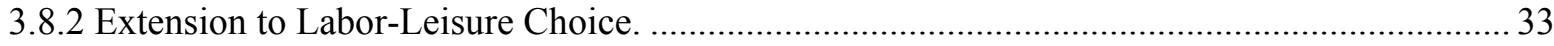

4. Market Productivity Cutoffs: Impact of Market Size and Preferences ................................................ 36

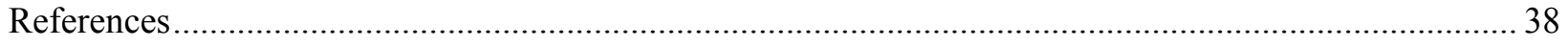

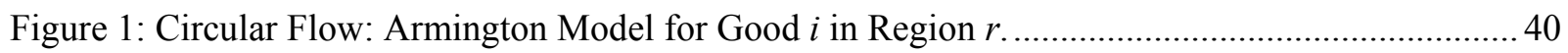




\section{Introduction}

In Balistreri and Tarr (2018), we assess the relative welfare impacts of trade cost reductions in models based on Armington (1969), Krugman (1980) and Melitz (2003). Balistreri and Tarr (2018) consider multi-sector, multi-region versions of these models with intermediates, labor-leisure choice, initial heterogeneous tariffs as well as iceberg costs, heterogeneous regions based on data, multiple factors of production and the possibility of sector-specific inputs. In section 2 of this paper, we lay out the equations of the models, with limited explanations that may be sufficient for understanding by an experienced international trade theorist.

Since we have not seen detailed derivations of the model with heterogeneous firms with the extensions we employ, in section 3 we take a textbook style approach to explanation and derivation of the equations of section 2 . We hope this will be a clear roadmap for understanding and constructing modern multi-sector, multi-region international trade models that must be fitted to real data.

In section 4 we show that additional fixed costs of exporting, iceberg costs and tariffs all lead to a higher zero-productivity cutoff for exporting than for sales in the home market. A special case of our model with homogeneous regions is consistent with the evidence that exporting firms are a minority of total firms in a region; it also produces the result of Melitz (2003), i.e., exporting firms are a proper subset of firms that sell in the home market. But with heterogeneous regions, we could find that some firms find it profitable to export to some markets without serving their home market. This could happen if there are large export markets relative to the home market or relatively weak home market preferences for the product of a sector. In his one-sector model with two heterogeneous regions, Feenstra (2010, p.13) also shows the possibility (that he assumes away) of firms exporting without selling in their home market. Our result generalizes the Feenstra result to an arbitrary number of sectors and heterogeneous regions.

\section{Equations of the Model}

\subsection{Notation}

2.1.1 Sets: $R$ is the set of all regions, indexed by $r$ or s. $I$ is the set of all goods and services, indexed by $i$ or $j$ with subsets $K \subseteq I$ as the set of Krugman sectors and the subset $M \subseteq I$ as the set of Melitz style sectors. We reserve the index $k$ for Krugman sectors and the index $m$ for Melitz sectors. $F$ is the set of factors, indexed by $f$, with the subset $\tilde{F} \subseteq F$ as the set of sector-specific factors. 


\subsubsection{Variables:}

$D_{r}$ Scalar index of "full" consumption in region $r$, equal to one in the benchmark equilibrium;"

$Y_{i r}$ Scalar indices in the use of the composite input by sector $i$ in region $r$; it $i$ s equal to one in the benchmark equilibrium so represents the proportional change. In Armington sectors composite input use is also output; but under monopolistic competition, they represent the proportional change in composite inputs used by firms to cover both fixed and variable costs.

$Q_{i r}$ Scalar indices for composite supply for good or service $i$ in region $r$, equal to one in the benchmark equilibrium; in Armington mode, this is an index of the Armington aggregate good; in the monopolistic competition models, it is the Dixit-Stiglitz aggregate.

$e_{r}$ Unit expenditure index (true cost of living index) in region $r$;

$c_{i r}$ Domestic price of the composite inpust. For monopolistically competitive firms it is the price of composite inputs used for both fixed and variable costs in region $r$;

$P_{i r}$ Price of goods and services (Dixit-Stiglitz price in monopolistic competition) in region $r$;

$w_{f r}$ Price of mobile primary factor $f$ in region $r$;

$\tilde{w}_{f i r}$ Price of specific primary factor $f$ in the sector $i$ in region $r$;

$n_{i r}$ Number of active firms for $i \in K$; number of firms that enter for $i \in M$;

$N_{m r s}$ Number of Melitz firms in sector m of region $r$ selling in region $s, m \in M$;

$p_{k r s}$ Gross firm-level price of Krugman firms from region $r$ selling in region $s, k \in K$;

$q_{k r s}$ Firm level quantity for Krugman firms from region $r$ selling in region $s, k \in K$;

$\tilde{p}_{m r s}$ Gross firm-level price of Melitz representative firms from region $r$ selling in region $s, m \in M$;

$\tilde{q}_{m r s}$ Firm-level quantity of Melitz representative firms from region $r$ selling in region $s, m \in M$;

$\tilde{\varphi}_{m r s}$ Firm-level productivity of Melitz representative firms from region $r$ selling in region s; $m \in M$;

$\boldsymbol{I}_{r}$ Nominal income of region $\mathrm{r}$ (measured in units of the numeraire). With labor-leisure choice, this includes the imputed value of leisure.

\subsection{Instruments}

$\tau_{i r s}$ Iceberg trade costs on exports of sector $i$ from region $r$ to region $\mathrm{s}$;

\footnotetext{
${ }^{1}$ With labor-leisure choice this includes the imputed value of leisure.
} 
$t_{i r s}$ Tariff rates in sector $i$ on imports into region $s$ from region $\mathrm{r}$.

\subsection{Parameters}

$d 0_{r}$ Benchmark value of full consumption in region $r ;^{2}$

$y 0_{i r}$ Benchmark value of the use of gross output of sector $i$ in region $r$;

$q 0_{i r}$ Benchmark value of composite domestic and imported supply in sector $i$ in region $r$;

$\alpha_{j i r}$ Benchmark share of intermediate input $j$ in gross output of sector $i$ in region $r$;

$\beta_{\text {fir }}$ Benchmark share of primary factor $f$ in the value-added of sector $i$ in region $r$;

$\mu_{r}$ Benchmark share of leisure in full consumption;

$\theta_{i r}$ Benchmark share of $i$ in total consumption of goods and services;

$\sigma^{A}$ Elasticity of substitution in Armington sectors between goods from different regions;

$\sigma^{K}$ Dixit-Stiglitz elasticity of substitution between firm varieties in Krugman sectors;

$\sigma^{M}$ Dixit-Stiglitz elasticity of substitution between firm varieties in Melitz sectors;

$\lambda_{i r s}^{A}$ Preference weight in Armington aggregation of regional varieties from region $r$ in region $s$;

$\lambda_{k r s}^{K}$ Preference weight in Krugman aggregation of firm varieties from region $r$ in region $s, k \in K$;

$\lambda_{m r s}^{M}$ Preference weight in Melitz aggregation of firm varieties from region $r$ in region $s, m \in M$;

$\sigma^{L}$ Elasticity of substitution between leisure and consumption of goods and services;

$\sigma^{T}$ Elasticity of substitution between intermediates and between intermediates and value-added;

$f_{k r}^{K}$ Fixed costs (in composite input units) of Krugman firms in sector $k$ of region $r, k \in K$;

$f_{m r s}^{M}$ Fixed costs of Melitz firms (in composite input units) in sector $m$ of region $r$ operating in region $s$, $m \in M$;

$f_{m r}^{E}$ Sunk entry costs (in composite input units) of Melitz firms in sector $m$ of region $r, m \in M$;

$a$ Pareto shape parameter;

$b$ Pareto lower support;

$\delta$ Annual probability of firm death in the Melitz model;

$\bar{F}_{f r}$ Endowment of mobile factor $f$ in region $r$.

$\overline{S F}_{\text {fir }}$ Endowment of specific factor $f$ in sector $i$ of region $r$;

\footnotetext{
${ }^{2}$ Includes the imputed value of leisure if there is a labor-leisure choice.
} 
For $f=$ labor, without labor-leisure choice, the initial labor supply is the total endowment. With labor-leisure choice, the total endowment is the time of the worker-consumer;

$\overline{B O P}_{r}$ Benchmark capital account surplus.

\subsection{Representing technologies and preferences using duality}

2.2.1 Preferences. With the option to include a labor-leisure choice, the unit expenditure function is given by

$$
e_{r}=\left[\mu_{r} w_{L r}^{1-\sigma^{L}}+\left(1-\mu_{r}\right)\left(\prod_{i \in I} P_{i r}^{\theta_{i r}}\right)^{1-\sigma^{L}}\right]^{1 /\left(1-\sigma^{L}\right)} \quad r \in R .
$$

If $\mu_{r}=0$ labor supply is perfectly inelastic; then the unit expenditure function reduces to only the Cobb-Douglas preference nest over goods and services.

2.2.2 Technology of the Composite Input. The production technology for the composite input in the dual is given by one of the following formulations. ${ }^{3}$ We always assume that value-added inputs combine in a Cobb-Douglas nest, but we employ multiple treatments of intermediates. If we assume that intermediates and a value-added composite substitute with an elasticity of substitution $\sigma^{T} \neq 1$, we have the cost function of (2.2).

$$
c_{i r}=\left[\sum_{j \in I} \alpha_{j i r} P_{j r}^{1-\sigma^{T}}+\left(1-\sum_{j \in I} \alpha_{j i r}\right)\left(\prod_{f \notin \tilde{F}}\left(w_{f r}\right)^{\beta_{f i r}} \prod_{f \in \tilde{F}}\left(\tilde{w}_{f i r}\right)^{\beta_{f i r}}\right)^{1-\sigma^{T}}\right]^{1 /\left(1-\sigma^{T}\right)} \quad i \in I, r \in R,
$$

where $\alpha_{j i r} \geq 0 ; \beta_{f i r} \geq 0 ; \sum_{f \in F} \beta_{f i r}=1$ and $\sum_{j \in I} \alpha_{j i r}+\left(\sum_{j \in I}\left(1-\alpha_{j i r}\right)\right)\left[\sum_{f \in F} \beta_{f i r}\right]=1$

If there are no intermediates, then the $\alpha_{j i r}$ parameters are all zero and we only have the Cobb-Douglas nest of primary factors. If $\sigma^{T}=1$, we have the cost function of Cobb-Douglas technology in (2.3).

$$
c_{i r}=\prod_{j \in I} P_{j r}^{\alpha_{j i r}} \prod_{f \notin \tilde{F}}\left(w_{f r}\right)^{\left(1-\sum_{j} \alpha_{j i r}\right) \beta_{f i r}} \prod_{f \in \tilde{F}}\left(\tilde{w}_{f i r}\right)^{\left(1-\sum_{j} \alpha_{j i r}\right) \beta_{f i r}} \quad i \in I, r \in R .
$$

If we adopt the single-composite intermediate treatment, then the price of intermediates is the unit expenditure function and the cost function is shown by (2.4).

$$
c_{i r}=e_{r}^{\sum_{j} \alpha_{j i r}} \prod_{f \notin \widetilde{F}}\left(w_{f r}\right)^{\left(1-\sum_{j} \alpha_{j i r}\right) \beta_{f i r}} \prod_{f \in \tilde{F}}\left(\tilde{w}_{f i r}\right)^{\left(1-\sum_{j} \alpha_{j i r}\right) \beta_{f i r}} \quad i \in I, r \in R
$$

\footnotetext{
${ }^{3}$ See Balistreri and Tarr (2018) for the characterization of the three intermediate demand structures in the primal, along with the labor-leisure choice model and its calibration based on estimates of compensated and uncompensated labor supply.
} 
In the case when we do not have any intermediates, the $\alpha$ share parameters in the above equations would all be zero.

2.2.3 Prices. The next set of equations indicates the dual price of the good or service in region $s$. For the Armington structure, we have a CES aggregation of the prices of regional varieties:

$$
P_{i s}=\left[\sum_{r \in R} \lambda_{i r s}^{A}\left[\left(1+t_{i r s}\right) \tau_{i r s} c_{i r}\right]^{1-\sigma^{A}}\right]^{1 /\left(1-\sigma^{A}\right)} \quad i \in I, s \in R .
$$

If we assume a monopolistic competition structure, the dual price is either a Dixit-Stiglitz aggregation of Krugman firm-level varieties, as:

$$
P_{k s}=\left[\sum_{r \in R} \lambda_{k r s}^{K} n_{k r} p_{k r s}^{1-\sigma^{K}}\right]^{1 /\left(1-\sigma^{K}\right)} \quad k \in K, S \in R
$$

or (as we show in section 3.5) an aggregation of Melitz representative firm varieties as:

$$
P_{m s}=\left[\sum_{r \in R} \lambda_{m r s}^{M} N_{m r s} \tilde{p}_{m r s}^{1-\sigma^{M}}\right]^{1 /\left(1-\sigma^{M}\right)} \quad m \in M, s \in R .
$$

\subsection{Krugman specific equations}

Consistent with the Dixit-Stiglitz aggregation, demand for a variety produced by an individual firm in region $r$ and sold in region $s$ is:

$$
q_{k r s}=\lambda_{k r s}^{K} q 0_{k s} Q_{k s}\left(\frac{P_{k s}}{p_{k r s}}\right)^{\sigma^{k}} \quad k \in K, r \in R, s \in R .
$$

Faced with this demand, the price that maximizes profit for the individual firm includes a markup above marginal costs:

$$
p_{k r s}=\frac{\left(1+t_{k r s}\right) \tau_{k r s} c_{k r}}{1-1 / \sigma^{K}} \quad k \in K, r \in R, s \in R
$$

Free entry leads to zero profits, so accumulated quasi-rents across all markets just cover fixed costs:

$$
\sum_{s \in R} \frac{p_{k r s} q_{k r s}}{\sigma^{K}\left(1+t_{k r s}\right)}=f_{k r}^{K} c_{k r} \quad k \in K, r \in R .
$$

Associated with the zero-profit condition is $n_{k r}$, the number of firms entered in sector $\mathrm{k}$ of region $\mathrm{r}$. 


\subsection{Melitz specific equations}

The Melitz equilibrium is defined by a representative firm (variety) on each bilateral trade link. For details of the derivation starting from the distribution of all firms, see section 3. Demand for the representative firm is given by:

$$
\tilde{q}_{m r s}=\lambda_{m r s}^{M} q 0_{m s} Q_{m s}\left(\frac{P_{m s}}{\tilde{p}_{m r s}}\right)^{\sigma^{M}} \quad m \in M, r \in R, s \in R ;
$$

Optimal pricing leads to:

$$
\tilde{p}_{m r s}=\frac{\left(1+t_{m r s}\right) \tau_{m r s} c_{m r}}{\tilde{\varphi}_{m r s}\left(1-1 / \sigma^{M}\right)} \quad m \in M, r \in R, s \in R .
$$

We need a condition that determines selection into each bilateral market. The marginal firm will earn zero profits. With a Pareto distribution and shape parameter $a$, the zero cutoff profit condition maps to the representative firm's profit by:

$$
\frac{\tilde{p}_{m r s} \tilde{q}_{m r s}}{\left(1+t_{m r s}\right)} \frac{a+1-\sigma^{M}}{a \sigma^{M}}=f_{m r s}^{M} c_{m r} \quad m \in M, r \in R, s \in R .
$$

We need a condition that determines how many firms enter (take a productivity draw). Equilibrium requires that a potential entrant have zero expected profits from potentially multiple markets; then expected profits across multiple markets just equal the annualized sunk costs of establishing a variety. With $\delta$ as the rate of firm death, this requires that:

$$
\sum_{s \in R}\left(\frac{N_{m r s}}{n_{m r}}\right) \frac{\tilde{p}_{m r s} \tilde{q}_{m r s}\left(\sigma^{M}-1\right)}{\left(1+t_{m r s}\right) a \sigma^{M}}=\delta f_{m r}^{E} c_{m r} \quad m \in M, r \in R .
$$

Finally, the productivity of the representative firm is:

$$
\tilde{\varphi}_{m r s}=b\left(\frac{N_{m r s}}{n_{m r}}\right)^{-1 / a}\left(\frac{a+1-\sigma^{M}}{a}\right)^{1 /\left(1-\sigma^{M}\right)} \quad m \in M, r \in R, s \in R .
$$

\subsection{Market Clearance}

We choose notation that makes explicit that we solve for percentage changes in variables. In the case of the supply of output in each sector in region $r$ (from both domestic and imported sources) we write the supply of output of sector $i$ in region $r$ as $q 0_{i r} Q_{i r}$; this is its value in the benchmark times a scalar multiple that has a value of one in the benchmark. Then the endogenous supply variable for which we solve, $Q_{i r}$, is the proportional change in the supply. Similarly, we define output (or composite inputs) and consumption by $y 0_{i r} Y_{i r}$ and $d 0_{r} D_{r}$, respectively, so that the variables (times 100) for which we solve are the percentage changes in composite input use and consumption. 
We first establish the market clearance conditions for supply and demand of goods and services available for domestic use. The demand for goods and services is derived by applying Shepard's Lemma to the above defined consumption and production technologies. The market clearance conditions of supply and demand are given by:

$$
q 0_{i r} Q_{i r}=d 0_{r} D_{r} \frac{\partial e_{r}}{\partial P_{i r}}+\sum_{j \in I} y 0_{j r} Y_{j r} \frac{\partial c_{j r}}{\partial P_{i r}} \quad i \in I, r \in R
$$

Next, we establish market clearance for the production of good $i$ in region $\mathrm{r}$ and all of its uses in all markets. Under Armington the associated price is simply marginal cost, $c_{i r}$, so market clearance is given by:

$$
y 0_{i r} Y_{i r}=\sum_{s \in R} \tau_{i r s} q 0_{i s} Q_{i s} \frac{\partial P_{i s}}{\partial\left[\left(1+t_{i r s}\right) \tau_{i r s} c_{i r}\right]} \quad i \in I, r \in R,
$$

For the monopolistic competition models, we must account for the use of output for fixed costs as well as variable costs. Under Krugman we have

$$
y 0_{k r} Y_{k r}=n_{k r}\left(f_{k r}^{K}+\sum_{s \in R} \tau_{k r s} q_{k r s}\right) \quad k \in K, r \in R ;
$$

and under Melitz we have:

$$
y 0_{m r} Y_{m r}=\delta f_{m r}^{E} n_{m r}+\sum_{s \in R} N_{m r s}\left(f_{m r s}^{M}+\frac{\tau_{m r s} \tilde{q}_{m r s}}{\tilde{\varphi}_{m r s}}\right) \quad m \in M, r \in R .
$$

For sector-specific primary factors, the market clearance condition is:

$$
\overline{S F}_{f i r}=y 0_{i r} Y_{i r} \frac{\partial c_{j r}}{\partial \tilde{w}_{f i r}} \quad f \in \tilde{F}, i \in I, r \in R .
$$

For primary mobile factors of production, we account for demand across different sectors:

$$
\bar{F}_{f r}=\sum_{i \in I} y 0_{i r} Y_{i r} \frac{\partial c_{j r}}{\partial w_{f r}}+d 0_{r} D_{r} \frac{\partial e_{r}}{\partial w_{f r}} \quad f \in F, f \notin \bar{F}, r \in R .
$$

Leisure demand is given by the final term on the right-hand side, which is non-zero only if the factor is labor and we have chosen a non-zero elasticity of labor supply.

Real Consumption and Welfare. In all of our model variations except one, intermediates are modeled as in either (2.2) or (2.3); then the quantity associated with real consumption is fully exhausted in final demand, giving us

$$
d 0_{r} D_{r}=\frac{\boldsymbol{I}_{r}}{e_{r}} \quad r \in R
$$


where the change in $\frac{\boldsymbol{I}_{r}}{e_{r}}$ is the Hicksian equivalent variation.

In the one model where we assume a single composite intermediate input as in (2.4), however, some of the consumption good is used in production. In that special case, market clearance of supply and demand of the consumption good is:

$$
d 0_{r} D_{r}=\frac{\boldsymbol{I}_{r}}{e_{r}}+\sum_{j \in I} y 0_{j r} Y_{j r} \frac{\partial c_{j r}}{\partial e_{r}} \quad r \in R,
$$

and Hicksian equivalent variation remains the change in $\frac{\boldsymbol{I}_{r}}{e_{r}}$.

\subsection{Income balance and numeraire}

2.5.1 Numeraire. The model is based on relative prices (the model is homogeneous of degree zero in nominal prices). We define the numeraire as the price of a unit of utility in the United States:

$$
e_{U S A} \equiv 1 \text {. }
$$

All prices are relative to this numeraire.

2.5.2 Income of the Representative Agent. In terms of units of the numeraire, we must have nominal income equal expenditures of the representative agent in region $r$. Income equals the value of factor endowments plus any tariff revenue plus the value of any capital account surplus. With no laborleisure choice, the initial total labor supply is the endowment. With labor-leisure choice, the endowment of the representative agent is the total time endowment; then income is "full" income, i.e., it includes the imputed value of leisure. Note that the model includes a constant balance of trade constraint measured in international transfer units.

$$
\begin{aligned}
& \boldsymbol{I}_{r}=\sum_{f \notin \tilde{F}} w_{f r} \bar{F}_{f r}+\sum_{f \in \tilde{F}} \sum_{i} \tilde{w}_{f r} \overline{S F}_{f i r}+\sum_{i \notin K \cup M} \sum_{s \in R} t_{i s r} c_{i s} \tau_{i s r} q 0_{i r} Q_{i r} \frac{\partial P_{i r}}{\partial\left[\left(1+t_{i s r}\right) \tau_{i s r} c_{i s}\right]} \\
& +\sum_{k \in K} \sum_{s \in R} t_{k s r} n_{k s} p_{k s r} q_{k s r} /\left(1+t_{k s r}\right)+\sum_{m \in M} \sum_{s \in R} t_{m s r} N_{m s r} \tilde{p}_{m s r} \tilde{q}_{m s r} /\left(1+t_{m s r}\right)+e_{\text {usa }} \overline{B O P}_{r}
\end{aligned}
$$

\section{Equations Explained}

\subsection{Preferences.}

With the option to include a labor-leisure choice, the unit expenditure function in region $r$ is 


$$
e_{r}=\left[\mu_{r} w_{L r}^{1-\sigma^{L}}+\left(1-\mu_{r}\right)\left(\prod_{i \in I} P_{i r}^{\theta_{i r}}\right)^{1-\sigma^{L}}\right]^{1 /\left(1-\sigma^{L}\right)} r \in R .
$$

Equation (3.1), which is equation (2.1) of the model, is dual to the following utility function defined over the consumption of leisure and goods and services.

$$
U_{r}=\left[\mu_{r}^{\frac{1}{\sigma^{L}}} l_{r}^{\frac{\sigma^{L}-1}{\sigma^{L}}}+\left(1-\mu_{r}\right)^{\frac{1}{\sigma^{L}}}\left(\prod_{i} C_{i r}^{\theta_{i r}}\right)^{\frac{\sigma^{L}-1}{\sigma^{L}}}\right]^{\frac{\sigma^{L}}{\sigma^{L}-1}} \quad r \in R
$$

where $l_{r}=$ leisure and $C_{i r}$ is consumption of the $i$-th composite good or service in region $r . P_{i r}$ is the price of units of the composite commodity of the $i$-th sector given by the price indices shown below in section 3.3, which depend on the market structure of the sector, and $w_{L r}$ is the wage rate in region $r$. The consumer maximizes utility, subject to her income constraint given by (2.25). Equation (3.1) follows from substitution of the optimum values of consumption and leisure into the utility function and setting utility equal to one so that we have the optimum values necessary to generate one unit of utility. We provide details of the derivation in section 3.8 below.

\subsection{Technology of the Composite Input.}

We next explain equations (2.2) and (2.3) of the model. As is common in the literature, ${ }^{4}$ we assume that the inputs required for both fixed and marginal costs are identical, and the costs of these inputs may be represented by a function that is a linearly homogeneous, quasi-concave composite function of all inputs. We always assume that value-added inputs combine in a Cobb-Douglas nest, but we employ multiple treatments of intermediates. With Cobb-Douglas demand for intermediates, the production technology for the composite input in the dual is given by (3.3):

3.2.1 Cobb-Douglas. With full Cobb-Douglas technologies, the unit cost function is:

$$
\begin{array}{r}
c_{i r}=\prod_{j \in I} P_{j r}^{\alpha_{j i r}} \prod_{f \notin \tilde{F}}\left(w_{f r}\right)^{\left(1-\sum_{j} \alpha_{j i r}\right) \beta_{f i r}} \prod_{f \in \tilde{F}}\left(\tilde{w}_{f i r}\right)^{\left(1-\sum_{j} \alpha_{j i r}\right) \beta_{f i r}} \quad i \in I, r \in R, \\
\alpha_{j i r} \geq 0 ; \beta_{f i r} \geq 0 ; \sum_{f \in F} \beta_{f i r}=1 \text { and } \sum_{j \in I} \alpha_{j i r}+\left(\sum_{j \in I}\left(1-\alpha_{j i r}\right)\right)\left[\sum_{f \in F} \beta_{f i r}\right]=1
\end{array}
$$

The unit cost function of (3.3) is dual to the Cobb-Douglas production function:

\footnotetext{
${ }^{4}$ See, for example, Helpman and Krugman (1985, p. 12), Costinot and Rodriguez-Clare (2013, equation 7) and
} Markusen, Rutherford and Tarr (2005, equations 5 and 6). 
$y 0_{i r} Y_{i r}=\Phi_{i r} \prod_{j \in I} I T_{j i r}^{\alpha_{j i r}} \prod_{f \notin \tilde{F}}\left(F_{f i r}\right)^{\left(1-\Sigma_{j} \alpha_{j i r}\right) \beta_{f i r}} \prod_{f \in \tilde{F}}\left(\tilde{F}_{f i r}\right)^{\left(1-\sum_{j} \alpha_{j i r}\right) \beta_{f i r}}$

$i \in I, r \in R$,

where in sector $i$ of region $r, y 0_{i r} Y_{i r}$ is both composite inputs and output in Armington sectors. In the monopolistic competition sectors, it is use of the composite input. $I T_{j i r}$ is intermediate use of the aggregate good (either Armington or Dixit-Stiglitz) from sector $j$ used an intermediates in sector $i$ of region $r ; F_{f i r}$ is use of primary mobile factor $f$ in sector $i$ of region $r ;, \tilde{F}_{f i r}$ is use of primary specific factor $f$ in sector $i$ of region $r$, and $\Phi_{i r}$ is the Cobb-Douglas scaling parameter used to assure consistency between the primal and the form of the cost function. We define composite inputs by $y 0_{i r} Y_{i r}$, where $y 0_{i r}$ is the benchmark value of composite input use and $Y_{i r}$ are the endogenous variables that take the value of one in the benchmark. This formulation makes it transparent that the endogenous variables for which we solve are the proportional changes. Minimization of the cost of acquiring one unit of the composite input subject to the production function in (3.4) yields the unit cost function (3.3). If there are no intermediates, then the $\alpha_{j i r}$ parameters are all zero and we only have the Cobb-Douglas nest of primary factors.

3.2.2 Constant Elasticity of Substitution (CES). If we assume that intermediates and a value-added composite substitute with an elasticity of substitution $\sigma^{T} \neq 1$, we have the unit cost function of (3.5).

$c_{i r}=\left[\sum_{j \in I} \alpha_{j i r} P_{j r}^{1-\sigma^{T}}+\left(1-\sum_{j \in I} \alpha_{j i r}\right)\left(\prod_{f \notin \tilde{F}}\left(w_{f r}\right)^{\beta_{f i r}} \prod_{f \in \tilde{F}}\left(\tilde{w}_{f i r}\right)^{\beta_{f i r}}\right)^{1-\sigma^{T}}\right]^{1 /\left(1-\sigma^{T}\right)} i \in I, r \in R$

The unit cost function of (3.5) is dual to the CES production function:

$$
\begin{aligned}
& y 0_{i r} Y_{i r}=\left[\sum_{j \in I} \alpha_{j i r}^{1 / \sigma^{T}}\left(I T_{j i r}\right)^{\left(\sigma^{T}-1\right) / \sigma^{T}}+\left(1-\sum_{j \in I} \alpha_{j i r}\right)^{1 / \sigma^{T}} \beta^{\sigma^{T}\left(\sigma^{T}-1\right)}\left(\prod_{f \notin \tilde{F}}\left(F_{f i r}\right)^{\beta_{f i r}} \prod_{f \in \tilde{F}}\left(\tilde{F}_{f i r}\right)^{\beta_{f i r}}\right)^{\left(\sigma^{T}-1\right) / \sigma^{T}}\right]^{\frac{\sigma^{T}}{\left(\sigma^{T}-1\right)}} \\
& \sigma^{T}>0 \quad \beta=\prod_{f \in F} \beta_{f i r}^{\beta_{f i r}} \quad i \in I, r \in R
\end{aligned}
$$


Minimization of the cost of acquiring one unit of the composite input subject to the production function in (3.6) yields the unit cost function (3.5). ${ }^{5}$ If there are no intermediates, then the $\alpha_{j i r}$ parameters are all zero and we only have the Cobb-Douglas nest of primary factors.

\subsection{Armington Prices and Quantities}

In figure 1, we display the circular flow of goods or services of a given sector $i$ in region $r$. In the Armington model, the price of good $i$ in region $r$ is its marginal cost, which is $c_{i r}$. The delivered price to region $s$ of good or service $i$ includes the iceberg and tariff costs, i.e., $p_{i r s}=\left(1+t_{i r s}\right) \tau_{i r s} c_{i r}$. With model equation (2.5) which we rewrite here as (3.7), we define preferences in in the perfectly competitive sectors in the dual and assume that the price of a good or service is given by the unit cost of the constant returns to sale CES aggregation of prices of varieties from different regions. We discuss the Dixit-Stiglitz price aggregates in the Krugman and Melitz models in sections 3.4 and 3.5.

$$
P_{i s}=\left[\sum_{r \in R} \lambda_{i r s}^{A}\left[\left(1+t_{i r s}\right) \tau_{i r s} c_{i r}\right]^{1-\sigma^{A}}\right]^{1 /\left(1-\sigma^{A}\right)} \quad i \in I, s \in R
$$

We note that the Armington price $P_{i s}$ is the price of the composite good or service $i$ in region $s$ available for all uses, which is for consumption or intermediates in our model. By defining the Armington aggregate price based on absorption shares (explained below in this subsection), we have a unique Armington price of goods or services in sector $i$ of region s for all uses. This is consistent with standard gravity formulations (e.g., Anderson and van Wincoop, 2003; Balistreri and Hillberry, 2007; and Bernard et al., 2003) and data limitations that do not distinguish whether imports are used in final demand or as intermediate inputs. It is also consistent with the standard monopolistic competition structure where there is a single price index representing a composite of different varieties.

The Armington price is dual to a good that is defined by the Armington aggregator function (3.8).

$$
q 0_{i s} Q_{i s}=\left[\sum_{r \in R}\left(\lambda_{i r s}^{A}\right)^{1 / \sigma^{A}} q_{i r s}^{\left(\sigma^{A}-1\right) / \sigma^{A}}\right]^{\frac{\sigma^{A}}{\sigma^{A}-1}}
$$

where in sector $i$ of region $s, q_{i r s}$ is the quantity of goods supplied by region $r$. The Armington good in any sector $i$ is an aggregate of the goods supplied from different regions of the model and expresses the total quantity of an aggregate Armington good that is available for consumption and intermediate use. The quantities supplied from the different regions are not consumed by the representative agent or used as

\footnotetext{
${ }^{5}$ The term with $\beta$ is a Cobb-Douglas scaling factor to assure consistency with the form of the cost function.
} 
intermediates independently: they are demanded for consumption or intermediates only as a component of the Armington aggregate. Given the prices $P_{i s}$, consumers and firms optimize the purchases of the aggregate Armington good based on their expenditure and cost functions, which in the initial equilibrium determine the parameters $\lambda_{\text {irs }}^{A}$ of the Armington aggregate.

We define the Armington composite quantity as $q 0_{i s} Q_{i s}$, where $q 0_{i s}$ is the benchmark value of composite Armington output of sector $i$ in region $s$ and $Q_{i s}$ is the associated endogenous variable that takes the value of one in the benchmark. Then $Q_{i s}$ are the proportional changes in the Armington composite good or service.

To obtain the CES preference weights in (3.7), denote by the superscript 0 the values of these prices in the benchmark equilibrium, $p_{i r s}^{0}=\left(1+t_{i r s}^{0}\right) \tau_{i r s}^{0} c_{i r}^{0}$. Similarly, let $v_{i r s}^{0}=$ value of sales in the initial equilibrium of good or service $i$ from region $r$ into region $s .{ }^{6}$ Then $v 0_{i s}=\sum_{r \in R} v_{i r s}^{0}$ is the initial value of total absorption of good or service $i$ in region $s$. We can define the value share of good or service $i$ from region $r$ in total absorption of good or service $i$ in region $s$ in the initial equilibrium as:

$$
v_{i r s}=\frac{v_{i r s}^{0}}{v 0_{i s}} \quad \text { where } \sum_{r \in R} v_{i r s}=1 ; v_{i r s} \geq 0
$$

Using the calibrated share form of the CES (Rutherford, 2002), for unit costs we have the following:

$$
P_{i s}=\left[\sum_{r \in R} v_{i r s}\left[\frac{\left(1+t_{i r s}\right) \tau_{i r s} c_{i r}}{\left(1+t_{i r s}^{0}\right) \tau_{i r s}^{0} c_{i r}^{0}}\right]^{1-\sigma^{A}}\right]^{1 /\left(1-\sigma^{A}\right)}
$$

Define $\lambda_{i r s}^{A}=v_{i r s}\left[\left(1+t_{i r s}^{0}\right) \tau_{i r s}^{0} c_{i r}^{0}\right]^{\sigma^{A}-1}$ and substitute this into the calibrated share form of the CES price aggregator to obtain (3.7).

\subsection{Krugman specific equations}

Total costs for Krugman firms consist of a fixed cost and constant marginal costs of total output. As discussed above, we assume that the costs of all inputs may be represented by a composite cost function (3.3) or (3.5). We further assume that the inputs required for both fixed and marginal costs are identical. If

\footnotetext{
${ }^{6}$ In order to develop models close to the models of Costinot and Rodriguez-Clare (2014), we assume all final demand is consumption demand.
} 
the firm produces any output, it incurs a fixed cost of $f_{k r}^{K}$ units of the composite input. Firms in region $r$ do not face an additional fixed cost of exporting to market $s \neq r$. All firms in a given region have identical costs, so we may represent total costs $T C_{k r}$ of all firms by a representative firm function:

$$
T C_{k r}=c_{k r}\left(f_{k r}^{K}+\sum_{s \in R} \tau_{k r s} q_{k r s}\right) \quad k \in K, r \in R
$$

We want to derive the demand for a variety of an individual firm in sector $k$ of region $r$ and sold in region $s$. Each firm chooses to produce a unique variety. Let $\omega_{k r}$ represent a variety produced by an individual firm in sector $k$ of region $r$. Define:

$p_{s}\left(\omega_{k r}\right)=$ the price of variety $\omega_{k r}$ is region s;

$q_{s}\left(\omega_{k r}\right)=$ the quantity of variety $\omega_{k r}$ is region s;

$\pi_{s}\left(\omega_{k r}\right)=$ the operating profit of variety $\omega_{k r}$ is region s (excludes the fixed costs of operation); and $V_{k r s}=$ the set of varieties from sector $k$ sold in region s by firms from region $r$.

3.4.1 Firm price, quantity and profit. We first write the Dixit-Stiglitz price index so that the individual firm varieties appear and the prices are not necessarily equal. We allow regional preference weights, but not firm level preference weights, and discuss calibration of the weights below. We have:

$$
P_{k s}=\left[\sum_{r \in R} \sum_{\omega_{k r} \in V_{k r s}} \lambda_{k r s}^{K} p_{s}\left(\omega_{k r}\right)^{1-\sigma^{K}}\right]^{1 /\left(1-\sigma^{K}\right)} .
$$

The Dixit-Stiglitz price index is dual to the following quantity index ${ }^{7}$ :

$$
q 0_{k s} Q_{k s}=\left[\sum_{r \in R}\left(\lambda_{k r s}^{K}\right)^{1 / \sigma^{K}} q_{k r s}^{\left(\sigma^{K}-1\right) / \sigma^{K}}\right]^{\frac{\sigma^{K}}{\sigma^{K}-1}}
$$

We seek the demand function for an individual variety, $\omega_{k r}^{\prime}$ in region $s$. Since $P_{k s}$ is the minimum cost of acquiring one unit of good or service $k$ in region $s$, and our technology is linear homogeneous, the

\footnotetext{
${ }^{7}$ We define the Dixit-Stiglitz composite quantity as $q 0_{k s} Q_{k s}$, where $q 0_{k s}$ is the benchmark value of composite Armington output of sector $i$ in region $s$ and $Q_{k s}$ is the associated endogenous variable that takes the value of one in the benchmark. A similar definition will apply in the Melitz model.
} 
conditional cost function of all varieties of good $\mathrm{k}$ in region s is: $q 0_{k s} Q_{k s} P_{k s}$. Then from Shephard's Lemma, the conditional demand function for an individual variety is $q 0_{k s} Q_{k s} \frac{\partial P_{k s}}{\partial p_{s}\left(\omega_{k r}^{\prime}\right)}$.

Define $Z_{k s}$ as the terms inside the brackets of equation (3.12) so that: $P_{k s}=Z_{k s}^{1 /\left(1-\sigma^{K}\right)}$. Then $\frac{\partial P_{k s}}{\partial p_{s}\left(\omega_{k r}^{\prime}\right)}=\frac{\left(1-\sigma^{K}\right)}{1-\sigma^{K}} Z_{k s}^{\frac{1}{1-\sigma^{K}}-1}\left(\lambda_{k r s}^{K} p_{s}\left(\omega_{k r}^{\prime}\right)^{-\sigma^{K}}\right)=P_{k s} Z_{k s}^{-1}\left(\lambda_{k r s}^{K} p_{s}\left(\omega_{k r}^{\prime}\right)^{-\sigma^{K}}\right)=\lambda_{k r s}^{K}\left(\frac{P_{k s}}{p_{s}\left(\omega_{k r}^{\prime}\right)}\right)^{\sigma^{K}}$

where for the last equality we used $Z_{k s}^{-1}=P_{k s}^{\sigma^{K}-1}$. The demand for the individual variety $\omega_{k r}^{\prime}$ is:

$$
q_{s}\left(\omega_{k r}^{\prime}\right)=\lambda_{k r s}^{K} q 0_{k s} Q_{k s}\left(\frac{P_{k s}}{p_{s}\left(\omega_{k r}^{\prime}\right)}\right)^{\sigma^{K}}
$$

Since choice of the variety $\omega_{k r}^{\prime}$ was arbitrary, we may write the demand for any variety as:

$$
q_{s}\left(\omega_{k r}\right)=\lambda_{k r s}^{K} q 0_{k s} Q_{k s}\left(\frac{P_{k s}}{p_{s}\left(\omega_{k r}\right)}\right)^{\sigma^{K}}
$$

We define prices inclusive of tariffs, but the firm does not receive the tariff revenue. Then revenue of the firm is $\frac{p_{s}\left(\omega_{k r}\right) q_{s}\left(\omega_{k r}\right)}{\left(1+t_{k r s}\right)}$.

The quantity delivered to the consumer is net of the iceberg costs, so the firm must produce $\tau_{k r s} q_{s}\left(\omega_{k r}\right)$ units in order for $q_{s}\left(\omega_{k r}\right)$ to be delivered to the consumer. Since the firm does not incur an additional fixed cost of exporting, we define operating profit for the individual firm in sector $k$ of region $r$ on sales in region $s$ as:

$$
\pi_{s}\left(\omega_{k r}\right)=\frac{p_{s}\left(\omega_{k r}\right) q_{s}\left(\omega_{k r}\right)}{\left(1+t_{k r s}\right)}-\tau_{k r s} c_{k r} q_{s}\left(\omega_{k r}\right) .
$$

The first-order condition for profit maximization on this link yields:

$$
\frac{\partial \pi_{s}\left(\omega_{k r}\right)}{\partial q_{s}\left(\omega_{k r}\right)}=\frac{p_{s}\left(\omega_{k r}\right)}{\left(1+t_{k r s}\right)}+\frac{q_{s}\left(\omega_{k r}\right)}{\left(1+t_{k r s}\right)} \frac{d p_{s}\left(\omega_{k r}\right)}{d q_{s}\left(\omega_{k r}\right)}-\tau_{k r s} c_{k r}=0
$$

Define $\Upsilon_{k r s}=\lambda_{k r s}^{K} q 0_{k s} Q_{k s} P_{k s}^{\sigma^{K}}$ so $q_{s}\left(\omega_{k r}\right)=\Upsilon_{k r s} p_{s}\left(\omega_{k r}\right)^{-\sigma^{K}}$. Since large group monopolistically competitive firms assume they do not impact aggregates, the firm assumes that its price does not impact $\Upsilon_{k r s}$. Using the Implicit Function Theorem, for the middle term in (3.16) we have: 


$$
\frac{q_{s}\left(\omega_{k r}\right)}{\left(1+t_{k r s}\right)} \frac{d p_{s}\left(\omega_{k r}\right)}{d q_{s}\left(\omega_{k r}\right)}=\frac{1}{\left(1+t_{k r s}\right)} \frac{q_{s}\left(\omega_{k r}\right)}{\frac{d q_{s}\left(\omega_{k r}\right)}{d p_{s}\left(\omega_{k r}\right)}}=\frac{\Upsilon_{k r s} p_{s}\left(\omega_{k r}\right)^{-\sigma^{K}}}{\left(1+t_{k r s}\right) \Upsilon_{k r s}\left(-\sigma^{K} p_{s}\left(\omega_{k r}\right)^{-\sigma^{K}-1}\right)}=-\frac{p_{s}\left(\omega_{k r}\right)}{\left(1+t_{k r s}\right) \sigma^{K}}
$$

Rearranging, the price that maximizes profit for the individual firm in sector $k$ of region $r$ selling in region $s$ includes a markup above marginal costs:

$$
p_{s}\left(\omega_{k r}\right)=\frac{\left(1+t_{k r s}\right) \tau_{k r s} c_{k r}}{1-1 / \sigma^{K}}=p_{k r s} \forall \omega_{k r} \quad k \in K, r \in R, s \in R, \omega_{k r} \in V_{k r s} .
$$

Firms charge a constant markup above marginal costs. Since costs are identical for all firms in a given sector and region, all firms in sector $k$ from region $r$ apply the same markup over costs we may drop the firm or variety index from the price equation and substitute $p_{k r s}$ for $p_{s}\left(\omega_{k r}\right)$. This establishes equation (2.9). Substitute $p_{k r s}$ for $p_{s}\left(\omega_{k r}\right)$ in the equation for demand for a variety (3.15). We see that all firms from sector $k$ in region $r$ produce the same quantity of sales in region $s$. Thus, we also drop the variety index regarding price, quantity and profits. In particular, we write the demand for a variety $\omega_{k r}$ in region $s$ as:

$$
q_{k r s}=\lambda_{k r s}^{K} q 0_{k s} Q_{k s}\left(\frac{P_{k s}}{p_{k r s}}\right)^{\sigma^{K}} \quad k \in K, r \in R, s \in R .
$$

This establishes model equation (2.8).

3.4.2 Free Entry Condition. Free entry leads to zero profits, so accumulated operating profits across all markets just cover fixed costs. Rearrange (3.17), so we have $\tau_{k r s} c_{k r}=\frac{p_{k r s}\left(1-1 / \sigma^{K}\right)}{\left(1+t_{k r s}\right)}$. Substitute for $\tau_{k r s} c_{k r}$ in the operating profits of any firm from region $r$ on sales to a particular region $s$. Operating profits are:

$$
\pi_{s}\left(\omega_{k r}\right)=\frac{p_{k r s} q_{k r s}}{\left(1+t_{k r s}\right)}-c_{k r s} \tau_{k r s} q_{k r s}=\frac{p_{k r s} q_{k r s}}{\left(1+t_{k r s}\right)}-\frac{p_{k r s}\left(1-1 / \sigma^{K}\right)}{\left(1+t_{k r s}\right)} q_{k r s}=\frac{p_{k r s} q_{k r s}}{\left(1+t_{k r s}\right) \sigma^{K}} .
$$

From (3.19) we see that any firm that is active in its home market will sell in all regions since operating profits are positive in all regions. That is, the index $s$ in the set $V_{k r s}$ is redundant. Summing over all regions $s$ yields the zero-profit condition, which is model equation (2.10): 


$$
\sum_{s \in R} \frac{p_{k r s} q_{k r s}}{\left(1+t_{k r s}\right) \sigma^{K}}=f_{k r}^{K} c_{k r} \quad k \in K, r \in R .
$$

Associated with the zero-profit condition is $n_{k r}$, the number of firms entered in sector $k$ of region $r$ Substitute $p_{k r s}$ for $p_{s}\left(\omega_{k r}\right)$ into the Dixit-Stiglitz disaggregated price index, (3.12), and use

$$
\begin{aligned}
\sum_{\omega_{k r} \in V_{k r s}} p_{k r s}{ }^{1-\sigma^{K}}=n_{k r} p_{k r s}{ }^{1-\sigma^{K}} \text { to obtain model equation (2.6): } & \\
P_{k s} & =\left[\sum_{r \in R} \lambda_{k r s}^{K} n_{k r} p_{k r s}^{1-\sigma^{K}}\right]^{1 /\left(1-\sigma^{K}\right)} \quad k \in K, s \in R ;
\end{aligned}
$$

\subsubsection{Preference Weights in the Dixit-Stiglitz Price Equation of the Krugman}

model. Using $v_{k r s}$ from (3.9), the calibrated share formula for the Dixit-Stiglitz price index is:

$$
P_{k s}=\left[\sum_{r \in R} v_{k r s} \frac{n_{k r} p_{k r s}^{1-\sigma^{K}}}{n_{k r s}^{0} *\left(p_{k r s}^{0}\right)^{1-\sigma^{K}}}\right]^{1 /\left(1-\sigma^{K}\right)}
$$

where the superscript 0 denotes the value of the variable in the benchmark equilibrium. We take $n_{k r s}^{0}=1^{8}$ and define

$$
\lambda_{k r s}^{K}=v_{k r s}\left(p_{k r s}^{o}\right)^{\sigma^{K}-1}=v_{k r s}\left[\frac{\left(1+t_{k r s}^{0}\right) \tau_{k r s}^{0} c_{k r}^{0}}{1-1 / \sigma^{K}}\right]^{\sigma^{K}-1}
$$

Substituting $\lambda_{k r s}^{K}$ into the calibrated share form of the CES price aggregator, we obtain(3.21), which is equation (2.6) of the model.

3.4.4 Constant Output per Firm. It helps with interpretation of results to show that output per firm is constant in this model. Substitute for price in (3.20) to get

$$
\sum_{s \in R} \frac{\left(\frac{\sigma^{k}}{\sigma^{k}-1}\right)\left(1+t_{k r s}\right) \tau_{k r s} c_{k r} q_{k r s}}{\sigma^{K}\left(1+t_{k r s}\right)}=f_{k r}^{K} c_{k r} .
$$

Rearrange to get:

$$
q_{k r}=\sum_{s \in R} \tau_{k r s} q_{k r s}=f_{k r}^{K}\left(\sigma^{K}-1\right)
$$

\footnotetext{
${ }^{8}$ We have shown that the welfare results are independent of the initial value of the number of Krugman firms.
} 
From (3.11), the left-hand side of (3.23) is total firm output Since the right-hand side of (3.23) is constant, output per firm is constant, i.e., there are no rationalization effects in this model and results differ from Armington only due to the Dixit-Stiglitz variety externality.

\subsection{Melitz specific equations}

3.5.1 Firm Basics. Since we desire to calibrate our model to real data, we generalize the model of Melitz (2003). Among our extensions are that we allow for asymmetry among the regions of the world, for multiple sectors, intermediates based on real data, the possibility of alternate elasticities of substitution in the cost function of the firm, labor-leisure choice, multiple factors of production, both mobile and specific factors of production, and initial tariffs in addition to iceberg trade costs. As in Melitz (2003), we assume there is a continuum of firms each choosing to produce a unique variety; let $\omega_{m r}$ represent a variety produced by an individual Melitz firm in sector $m$ of region $r$. All Melitz firms in sector $m$ of region $r$ incur a sunk entry cost (equal to $c_{m r} f_{m r}^{E}$ ) of entering the market prior to knowing its productivity. All these firms also incur a fixed cost of selling in any market $\left(c_{m r} f_{m r s}^{M}\right)$. Unlike in Melitz (2003), we do not assume that $r \neq s \Rightarrow f_{m r s}^{M}>f_{m r r}^{M}$. This latter condition assumes that if a firm chooses to export, it incurs an additional fixed cost of serving any market other than its home market. With homogeneous regions, as in Melitz (2003), this latter condition is required to produce the result that all active firms sell in the home market, but only a fraction of them export. We show in section 4 , however, that with heterogeneous regions, it is possible that some firms export without selling in the home market. This could occur, for example, if the size of the home market is small relative to the export market or if the preferences of home market consumers for the product the firm produces is low compared with preferences of consumers in some foreign markets. In our calibration of the model, we allow the data to tell us the relationship between home market and foreign market fixed costs.

After entering the market, the firm receives a productivity level $\varphi_{m r}$ as a random draw from a Pareto probability distribution (untruncated above) with shape parameter $a$ and lower bound $b$. We replace the variety indicator from the price, quantity, profit and revenue functions with the productivity of the firm.

For a firm in sector $m$ of region $r$ producing a variety with productivity $\varphi_{m r}$ and selling in region $s$, define:

$p_{s}\left(\varphi_{m r}\right)=$ the firm's gross price in region $s$;

$q_{s}\left(\varphi_{m r}\right)=$ the firm's quantity of sales in region $s$ 
$\pi_{s}\left(\varphi_{m r}\right)=$ the firm's profits in region $s$

$r_{s}\left(\varphi_{m r}\right)=$ the firms' revenue in region $s$.

Define $V_{m r s}$ as the set of productivities of firms in sector $m$ of region $r$ that are sold in region $s$.

The sets of productivity values $V_{m r s}$ will have different minimum values depending on the export market

$s$. Define $T C_{m r}\left(\varphi_{m r}\right)=$ total operating costs of the firm in sector $m$ of region $r$. Total operating costs

for active Melitz firms with productivity $\varphi_{m r}$, include the (constant) marginal costs of total output and the fixed cost of serving any market in which they are active, but they exclude the fixed entry costs:

$$
T C_{m r}\left(\varphi_{m r}\right)=c_{m r}\left(\sum_{s \in R} f_{m r s}^{M}+\frac{1}{\varphi_{m r}} \sum_{s \in R} \tau_{k r s} q_{s}\left(\varphi_{m r}\right)\right)
$$

where $q_{s}\left(\varphi_{m r}\right)=0 \Rightarrow f_{m r s}^{M}=0 .{ }^{9}$ Fixed entry costs are equal to: $c_{m r} f_{m r}^{E}$.

3.5.2 Firm Level Prices, Quantity, Profits and Revenue. There is a continuum of demand functions. The obtain the demand for the variety of an individual Melitz firm in sector $\mathrm{m}$ of region $\mathrm{r}$ selling in region s, we write the Dixit-Stiglitz price index as $P_{m s}$ :

$$
P_{m s}=\left[\sum_{r \in R} \lambda_{m r s}^{M} \int_{\varphi_{m r} \in V_{m r s}} p_{s}\left(\varphi_{m r}\right)^{1-\sigma^{M}} d \varphi_{m r}\right]^{1 /\left(1-\sigma^{M}\right)} \sigma^{M}>1
$$

The Dixit-Stiglitz price index is dual to the following quantity index:

$$
q 0_{m s} Q_{m s}=\left[\sum_{r \in R}\left(\lambda_{m r s}^{M}\right)^{1 / \sigma^{M}} \int_{\varphi_{m r} \in V_{m r s}} q_{m r s}^{\left(\sigma^{M}-1\right) / \sigma^{M}} d \varphi_{m r}\right]^{\frac{\sigma^{M}}{\sigma^{M}-1}}
$$

We want to derive the demand for an individual variety. Denote an individual variety in sector $m$ of region $r$ as $\varphi_{m r}^{\prime}$. Analogous to the Krugman case, we use the linear homogeneous property of the CES and the fact that Dixit-Stiglitz price in (3.25) is the minimum cost of acquiring one unit of the DixitStiglitz good to write the conditional cost function as: $q 0_{m s} Q_{m s} P_{m s}$. We then apply Shephard's Lemma

\footnotetext{
${ }^{9}$ As in the Krugman model, as common in the literature, we assume that the inputs required for all fixed costs and marginal costs are identical, and the costs of these inputs may be represented by a function that is a linearly homogeneous, quasi-concave composite function of all inputs. In the heterogeneous firms case, this assumption also applies to the sunk entry costs.
} 
to the conditional cost function to get that the demand function of an individual variety as:

$$
\begin{aligned}
& q 0_{m s} Q_{m s} \frac{\partial P_{m s}}{\partial p_{s}\left(\omega_{m r}^{\prime}\right)} . \\
& \text { Define } Z_{m s} \text { as the terms inside the brackets of }(3.25): P_{m s}=Z_{m s}^{1 /\left(1-\sigma^{M}\right)} . \text { We have: } \\
& \frac{\partial P_{m s}}{\partial p_{s}\left(\varphi_{m r}^{\prime}\right)}=\frac{\lambda_{m r s}^{M}\left(1-\sigma^{M}\right)}{1-\sigma^{M}} Z_{m s}^{\left(\frac{1}{1-\sigma^{M}}-1\right)} p_{s}\left(\varphi_{m r}^{\prime}\right)^{-\sigma^{M}}=\lambda_{m r s}^{M} P_{m s} Z_{m s}^{-1} p_{s}\left(\varphi_{m r}^{\prime}\right)^{-\sigma^{M}}=\lambda_{m r s}^{M}\left(\frac{P_{m s}}{p_{s}\left(\varphi_{m r}^{\prime}\right)}\right)^{\sigma^{M}}
\end{aligned}
$$

where we used the property that:

$$
\frac{\partial\left[\int_{\varphi_{m r} \in V_{m r s}} p_{s}\left(\varphi_{m r}\right)^{1-\sigma^{M}} d \varphi_{m r}\right]}{\partial p_{s}\left(\varphi_{m r}^{\prime}\right)}=\left(1-\sigma^{M}\right) p_{s}\left(\varphi_{m r}^{\prime}\right)^{-\sigma^{M}} \cdot{ }^{10}
$$

Then the demand for $q_{s}\left(\varphi_{m r}^{\prime}\right)$ is:

${ }^{10}$ In order to show the demand for an individual variety with a continuum of varieties, authors implicitly or explicitly use the property in equation (3.27). But we have not seen an explanation or proof of this property in print. Here we summarize the intuition for this property and the on-line proofs we have found.

For intuition, suppose we had a sum of a finite number of varieties as in our Krugman model:

$$
S=\sum_{\varphi_{m r} \in V_{m r s}} p_{s}\left(\varphi_{m r}\right)^{1-\sigma^{M}}
$$

The partial derivative of this sum with respect to a particular term (or variety) $p_{s}\left(\varphi_{m r}^{\prime}\right)$ is straightforward from basic calculus and equals

$$
\frac{\partial S}{\partial p_{s}\left(\varphi_{m r}^{\prime}\right)}=\left(1-\sigma^{M}\right) p_{s}\left(\varphi_{m r}^{\prime}\right)^{-\sigma^{M}}
$$

which is the right-hand side of equation (3.27). The partial derivative of this sum is unchanged for any finite number of varieties. Intuitively, as the finite number of varieties becomes very large, this partial derivative should approach the partial derivative of the continuum case in (3.27).

We have seen three proofs on-line. The first one is a proof of the intuitive argument above. At the first link below, Alecos Papadopoulos argues that, based on a theorem by Craven (1970) in the Bulletin of the Australian Mathematical Society, we may differentiate the integral as if it were a finite sum. A second proof applies a theorem in the calculus of variations applied to CES optimization problems with a continuum of commodities. It is due to J. Bhattacharya (2014), "Consumer Optimum in an Economy with a Continuum of Commodities," November 23. Available at: https://economics.stackexchange.com/questions/210/consumer-optimum-in-an-economy-with-acontinuum-of-commodities. A third proof relies on the concept of a functional derivative and may be found at the link: "Regarding a consumption aggregator: How do I differentiate under the integral?" November 3, 2016. Available at: https://economics.stackexchange.com/questions/14068/regarding-a-consumption-aggregatorhow-do-i-differentiate-under-the-integral-si?noredirect=1\&lq=1 . 


$$
q_{s}\left(\varphi_{m r}^{\prime}\right)=\lambda_{m r s}^{M} q 0_{m s} Q_{m s}\left(\frac{P_{m s}}{p_{s}\left(\varphi_{m r}^{\prime}\right)}\right)^{\sigma^{M}}
$$

Since the selection of the individual variety $\varphi_{m r}^{\prime}$ was arbitrary, (3.28) holds for any variety $\varphi_{m r}$ and we may replace $\varphi_{m r}^{\prime}$ with $\varphi_{m r}$ in (3.28) yielding:

$$
q_{s}\left(\varphi_{m r}\right)=\lambda_{m r s}^{M} q 0_{m s} Q_{m s}\left(\frac{P_{m s}}{p_{s}\left(\varphi_{m r}\right)}\right)^{\sigma^{M}}
$$

To simplify notation, define $\Upsilon_{m r s}$ as the "aggregates" in the demand curve of the individual firm:

$$
\begin{aligned}
& \Upsilon_{m r s}=\lambda_{m r s}^{M} q 0_{m s} Q_{m s} P_{m s}^{\sigma^{M}} \text {. Then } \\
& \qquad q_{s}\left(\varphi_{m r}\right)=\Upsilon_{m r s} p_{s}\left(\varphi_{m r}\right)^{-\sigma^{M}} .
\end{aligned}
$$

Profit for the individual firm in sector $m$ of region $r$ selling in region $s$ is:

$$
\pi_{s}\left(\varphi_{m r}\right)=\frac{p_{m r s}\left(\varphi_{m r}\right) q_{s}\left(\varphi_{m r}\right)}{\left(1+t_{m r s}\right)}-\tau_{m r s}\left(\frac{c_{k r}}{\varphi_{m r}}\right) q_{s}\left(\varphi_{m r}\right)-c_{m r} f_{m r s}^{M}
$$

Profit maximization analogous to the Krugman case above yields the optimal price for the individual firm

$$
p_{s}\left(\varphi_{m r}\right)=\frac{\left(1+t_{m r s}\right) \tau_{m r s} c_{m r}}{\varphi_{m r}\left(1-1 / \sigma^{M}\right)}
$$

We see that more productive firms charge lower prices, i.e., $\frac{\partial p_{s}\left(\varphi_{m r}\right)}{\partial \varphi_{m r}}<0$, and from the demand curve in (3.28), sell larger quantities.

Since in the home market tariffs are zero and iceberg costs are unity, the firm's export prices to market $s$ differ from its home market price by a term that is the product of its iceberg and tariff costs.

$$
p_{r}\left(\varphi_{m r}\right)=\frac{c_{m r}}{\varphi_{m r}\left(1-1 / \sigma^{M}\right)} \quad \text { and } \quad p_{s}\left(\varphi_{m r}\right)=\left(1+t_{m r s}\right) \tau_{m r s} p_{r}\left(\varphi_{m r}\right)
$$

Revenue of the firm in sector $m$ from region $r$ with productivity $\varphi_{m r}$ on sales in region $s$ is

$$
r_{s}\left(\varphi_{m r}\right)=\frac{p_{s}\left(\varphi_{m r}\right) q_{s}\left(\varphi_{m r}\right)}{\left(1+t_{m r s}\right)}=\frac{p_{s}\left(\varphi_{m r}\right)\left(\Upsilon_{m r s} p_{s}\left(\varphi_{m r}\right)^{-\sigma^{M}}\right)}{\left(1+t_{m r s}\right)}=\frac{\Upsilon_{m r s} p_{s}\left(\varphi_{m r}\right)^{1-\sigma^{M}}}{\left(1+t_{m r s}\right)}
$$

We note that $\frac{\partial r_{s}\left(\varphi_{m r}\right)}{\partial \varphi_{m r}}>0$, revenue on exports to market $s$ increases with the firm's productivity. 
The ratio of the revenue of any two firms in sector $m$ of region $r$ on their sales in region $s$ may be expressed as a function of the ratio of productivities and the Dixit-Stiglitz elasticity. To simplify notation, define $k_{m r s}=\frac{\left(1+t_{m r s}\right) \tau_{m r s} c_{m r}}{\left(1-1 / \sigma^{M}\right)}$, so $p_{s}\left(\varphi_{m r}\right)=\frac{k_{m r s}}{\varphi_{m r}}$. Then

$$
\frac{r_{s}\left(\varphi_{m r}^{\prime \prime}\right)}{r_{s}\left(\varphi_{m r}^{\prime}\right)}=\frac{\Upsilon_{m r s} p_{s}\left(\varphi_{m r}^{\prime \prime}\right)^{1-\sigma^{M}}}{\Upsilon_{m r s} p_{s}\left(\varphi_{m r}^{\prime}\right)^{1-\sigma^{M}}}=\left[\frac{\frac{k_{m r s}}{\varphi_{m r}^{\prime \prime}}}{\frac{k_{m r s}}{\varphi_{m r}^{\prime}}}\right]^{1-\sigma^{M}}=\left(\frac{\varphi_{m r}^{\prime \prime}}{\varphi_{m r}^{\prime}}\right)^{\sigma^{M}-1} \varphi_{m r}^{\prime \prime}
$$

Rearrange (3.31) as $\frac{p_{s}\left(\varphi_{m r}\right)\left(1-1 / \sigma^{M}\right)}{\left(1+t_{m r s}\right)}=\frac{\tau_{m r s} c_{m r}}{\varphi_{m r}}$. Substitute for $\frac{\tau_{m r s} c_{m r}}{\varphi_{m r}}$ in profit of the firm in market $s$. Operating profits in market $s$ are:

$$
\pi_{s}\left(\varphi_{m r}\right)+c_{m r} f_{m r s}^{M}=\frac{p_{s}\left(\varphi_{m r}\right) q_{s}\left(\varphi_{m r}\right)}{\left(1+t_{m r s}\right)}-\frac{\left(1-1 / \sigma^{M}\right)}{\left(1+t_{m r s}\right)} p_{s}\left(\varphi_{m r}\right) q_{s}\left(\varphi_{m r}\right)=\frac{p_{s}\left(\varphi_{m r}\right) q_{s}\left(\varphi_{m r}\right)}{\left(1+t_{m r s}\right) \sigma^{M}}=\frac{r_{s}\left(\varphi_{m r}\right)}{\sigma^{M}} .
$$

The firm's profits on sales in market $s$ are:

$$
\pi_{s}\left(\varphi_{m r}\right)=\frac{r_{s}\left(\varphi_{m r}\right)}{\sigma^{M}}-c_{m r} f_{m r s}^{M}
$$

Define $\varphi_{m r s}^{*}$ as the productivity cutoff for firms in sector $m$ of region $r$ selling in region $s$. The productivity draw of firms does not depend on the destination market. Due to our asymmetry, however, the zero-profit productivity cutoff depends on the parameters of the export market. Therefore, the productivity value that yields zero profit may be represented as:

$$
\pi_{s}\left(\varphi_{m r s}^{*}\right)=0 \Leftrightarrow \frac{r_{s}\left(\varphi_{m r s}^{*}\right)}{\sigma^{M}}=c_{m r} f_{m r s}^{M} .
$$

From the (3.34), take $\varphi_{m r}^{\prime}=\varphi_{m r s}^{*}$; we have

$$
r_{s}\left(\varphi_{m r}\right)=r_{s}\left(\varphi_{m r s}^{*}\right)\left(\frac{\varphi_{m r}}{\varphi_{m r s}^{*}}\right)^{\sigma^{M}-1}=\sigma^{M} c_{m r} f_{m r s}^{M}\left(\frac{\varphi_{m r}}{\varphi_{m r s}^{*}}\right)^{\sigma^{M}-1}
$$

Substitute for $r_{s}\left(\varphi_{m r}\right)$ from (3.37) into (3.35) for profits. We have: 


$$
\begin{gathered}
\pi_{s}\left(\varphi_{m r}\right)=\frac{\sigma^{M} c_{m r} f_{m r s}^{M}\left(\frac{\varphi_{m r}}{\varphi_{m r s}^{*}}\right)^{\sigma^{M}-1}}{\sigma^{M}}-c_{m r} f_{m r s}^{M}=c_{m r} f_{m r s}^{M}\left[\left(\frac{\varphi_{m r}}{\varphi_{m r s}^{*}}\right)^{\sigma^{M}-1}-1\right]>0 \quad \text { iff } \quad \varphi_{m r}>\varphi_{m r s}^{*} \\
\pi_{s}\left(\varphi_{m r}\right)=0 \quad \text { if } \varphi_{m r} \leq \varphi_{m r s}^{*}
\end{gathered}
$$

For productivity values below the zero-profit cutoff, the firm will not sell in market $s$ : $q_{s}\left(\varphi_{m r}\right)=0$ if $\varphi_{m r}<\varphi_{m r s}^{*}$.

3.5.3 Aggregate and Representative Firm Variables. For the definition of the aggregate variables, we may retain generality of the pdf, subject to the constraint that the relevant integrals below exist. Define the continuous probability density function (pdf) of the productivities faced by firms in sector $m$ of region $r$ as $g\left(\varphi_{m r}\right)$, and let $G\left(\varphi_{m r}\right)$ be the cumulative distribution function for this pdf.

Given that firms from sector $m$ of region $r$ are not active in a market $s$ for $\varphi_{m r}<\varphi_{m r s}^{*}$, then $1-G\left(\varphi_{m r s}^{*}\right)$ is the probability that the firm is active in market $s$. The conditional pdf, conditional on the firm being active in market $s$, is:

$$
\frac{g\left(\varphi_{m r}\right)}{1-G\left(\varphi_{m r s}^{*}\right)} \text { if } \varphi_{m r} \geq \varphi_{m r s}^{*} ;=0 \text { otherwise }
$$

Define the productivity of our representative firm from sector $m$ in region $r$ that is active in export market $s$ as $\tilde{\varphi}_{m r s}$ where:

$$
\tilde{\varphi}_{m r s}=\left[\int_{\varphi_{m r s}^{*}}^{\infty} \varphi_{m r}^{\sigma^{M}-1} \frac{g\left(\varphi_{m r}\right)}{1-G\left(\varphi_{m r s}^{*}\right)} d \varphi_{m r}\right]^{\frac{1}{\sigma^{M}-1}}
$$

The productivity of our representative firm is indexed by the destination market since the zero-profit productivity value cutoff depends on the destination market. ${ }^{11}$ Substitute the particular productivity value $\tilde{\varphi}_{m r s}$ for $\varphi_{m r}$ into the optimal price equation of the firm. We have

$$
p_{s}\left(\tilde{\varphi}_{m r s}\right)=\tilde{p}_{m r s}=\frac{\left(1+t_{m r s}\right) \tau_{m r s} c_{m r}}{\tilde{\varphi}_{m r s}\left(1-1 / \sigma^{M}\right)}=\frac{k_{m r s}}{\tilde{\varphi}_{m r s}}
$$

\footnotetext{
${ }^{11} \tilde{\varphi}_{m r s}$ could also be equivalently defined as the expected value of $\varphi_{m r s}^{\sigma^{M}-1}$ conditional on the productivity exceeding the zero-cutoff productivity for sales in market $s$.
} 
which is equation (2.12) of the equations of the model, where we use the notation $p_{s}\left(\tilde{\varphi}_{m r s}\right) \equiv \tilde{p}_{m r s}$. Similarly for quantity, revenue and profits, define: $\tilde{q}_{m r s} \equiv q_{s}\left(\tilde{\varphi}_{m r s}\right) ; r_{s}\left(\tilde{\varphi}_{m r s}\right) \equiv \tilde{r}_{m r s} ;$ and $\pi_{s}\left(\tilde{\varphi}_{m r s}\right) \equiv \tilde{\pi}_{m r s}$.

Using our conditional pdf, rewrite the Dixit-Stiglitz price index of (3.25):

$$
P_{m s}=\left[\sum_{r \in R} \lambda_{m r s}^{M} \int_{\varphi_{m r s}^{*}}^{\infty} N_{m r s} p_{s}\left(\varphi_{m r}\right)^{1-\sigma^{M}} \frac{g\left(\varphi_{m r}\right)}{1-G\left(\varphi_{m r s}^{*}\right)} d \varphi_{m r}\right]^{1 /\left(1-\sigma^{M}\right)}
$$

where $N_{m r s}$ is the mass of firms in sector $m$ of region $r$ that sell in region $s$.

The value of the integral in equation (3.41) is:

$$
\begin{aligned}
& \int_{\varphi_{m r s}^{*}}^{\infty} N_{m r s} p_{s}\left(\varphi_{m r}\right)^{1-\sigma^{M}} \frac{g\left(\varphi_{m r}\right)}{1-G\left(\varphi_{m r s}^{*}\right)} d \varphi_{m r}=N_{m r s} k_{m r s}^{1-\sigma^{M}} \int_{\varphi_{m r s}^{*}}^{\infty} \varphi_{m r}^{\sigma^{M}-1} \frac{g\left(\varphi_{m r}\right)}{1-G\left(\varphi_{m r s}^{*}\right)} d \varphi_{m r} \\
& =N_{m r s} k_{m r s}^{1-\sigma^{M}} \tilde{\varphi}_{m r s}^{\sigma^{M}-1}=N_{m r s} p\left(\tilde{\varphi}_{m r s}\right)^{1-\sigma^{M}}
\end{aligned}
$$

Substitute $N_{m r s} p\left(\tilde{\varphi}_{m r s}\right)^{1-\sigma^{M}}$ for the integral in (3.41) to rewrite the Dixit-Stiglitz price index as:

$$
P_{m s}=\left[\sum_{r \in R} \lambda_{m r s}^{M} N_{m r s} \tilde{p}_{m r s}^{1-\sigma^{M}}\right]^{1 /\left(1-\sigma^{M}\right)}
$$

which is equation (2.7) of the equations of the model.

Since $\frac{\partial P_{m s}}{\partial N_{m r s}}<0$, the Dixit-Stiglitz price index for good $m$ in region $s$, declines in the mass of varieties for any region $r$.

In (3.29), choose $\varphi_{m r s}=\tilde{\varphi}_{m r s}$; then the demand for the representative variety is:

$$
\tilde{q}_{m r s}=q_{s}\left(\tilde{\varphi}_{m r s}\right)=\lambda_{m r s}^{M} q 0_{m s} Q_{m s}\left(\frac{P_{m s}}{\tilde{p}_{m r s}}\right)^{\sigma^{M}}=\Upsilon_{m r s} \tilde{p}_{m r s}^{-\sigma^{M}}
$$

which is equation (2.11) of the equations of the model.

Using (3.33), the expected revenue for an individual firm in sector $m$ of region $r$ on sales in region $s$, conditional on the firm being active in region $s$, is:

$$
E\left[r_{s}\left(\varphi_{m r}\right)\right]=E\left[\frac{p_{s}\left(\varphi_{m r}\right) q_{s}\left(\varphi_{m r}\right)}{1+t_{m r s}}\right]=\frac{\Upsilon_{m r s}}{1+t_{m r s}} \int_{\varphi_{m r s}^{*}}^{\infty} p_{s}\left(\varphi_{m r}\right)^{1-\sigma^{M}} \frac{g\left(\varphi_{m r}\right)}{1-G\left(\varphi_{m r s}^{*}\right)} d \varphi_{m r}
$$




$$
\begin{aligned}
& =\frac{\Upsilon_{m r s} k_{m r s}^{1-\sigma^{M}}}{1+t_{m r s}} \int_{\varphi_{m r s}^{*}}^{\infty} \varphi_{m r}^{\sigma^{M}-1} \frac{g\left(\varphi_{m r}\right)}{1-G\left(\varphi_{m s s}^{*}\right)} d \varphi_{m r}=\frac{\Upsilon_{m r s} k_{m r s}^{1-\sigma^{M}}}{1+t_{m r s}} \tilde{\varphi}_{m r s}^{\sigma^{M}-1} \\
& =\frac{\Upsilon_{m r s}}{1+t_{m r s}} p_{s}\left(\tilde{\varphi}_{m r s}\right)^{1-\sigma^{M}}=r_{s}\left(\tilde{\varphi}_{m r s}\right)=\tilde{r}_{m r s}
\end{aligned}
$$

For aggregate revenue, $R_{m r s}$, for all firms in sector $m$ of region $r$ on sales in region $s$, we must aggregate over the mass of firms. This is:

$$
R_{m r s}=\int_{\varphi_{m r s}^{*}}^{\infty} N_{m r s} r_{s}\left(\varphi_{m r}\right) \frac{g\left(\varphi_{m r}\right)}{1-G\left(\varphi_{m r s}^{*}\right)} d \varphi_{m r}=N_{m r s} r_{s}\left(\tilde{\varphi}_{m r s}\right)
$$

For aggregate profits, we use (3.35). The conditional expected profits for an individual firm in sector $m$ of region $r$ on sales in region $s$ are:

$$
E\left[\pi_{s}\left(\varphi_{m r}\right)\right]=\int_{\varphi_{m i s}}^{\infty}\left[\frac{r_{s}\left(\varphi_{m r}\right)}{\sigma^{M}}-c_{m r} f_{m r s}^{M}\right] \frac{g\left(\varphi_{m r}\right)}{1-G\left(\varphi_{m r s}^{*}\right)} d \varphi_{m r}=\frac{r_{s}\left(\tilde{\varphi}_{m s}\right)}{\sigma^{M}}-c_{m r} f_{m r s}^{M}=\pi_{s}\left(\tilde{\varphi}_{m s s}\right)=\tilde{\pi}_{m s s}
$$

For aggregate profits for all firms, $\Pi_{m r s}$, in sector $m$ of region $r$ on sales in region $s$, we must aggregate over the mass of firms:

$$
\Pi_{m r s}=\int_{\varphi_{m r s}^{*}}^{\infty} N_{m r s} \pi_{s}\left(\varphi_{m r}\right) \frac{g\left(\varphi_{m r}\right)}{1-G\left(\varphi_{m r s}^{*}\right)} d \varphi_{m r}=N_{m r s} \tilde{\pi}_{m r s}
$$

3.5.4 The Pareto Distribution. The free-entry equilibrium condition, the zero-profit cutoffs and the representative firm productivity level depend on the pdf. We assume a Pareto pdf that is untruncated above. We have

$$
g(\varphi)=\frac{a b^{a}}{\varphi^{a+1}} \quad \varphi \geq b>0 ; \text { equal zero otherwise, where } a \text { and } b \text { are positive. }
$$

The cumulative distribution function for the Pareto distribution is: $G(y)=1-\left(\frac{b}{y}\right)^{a} y \geq b>0$. Taking $y=\varphi_{m r s}^{*}$ in the cumulative distribution function, the conditional Pareto pdf (conditional on the productivity exceeding $\varphi_{m r s}^{*}$ ) is:

$$
\frac{g\left(\varphi_{m r}\right)}{1-G\left(\varphi_{m r s}^{*}\right)}=\frac{a b^{a}}{\varphi^{a+1}}\left(\frac{\varphi_{m r s}^{*}}{b}\right)^{a}=\frac{a \varphi_{m r s}^{* a}}{\varphi_{m r}^{a+1}} \text { if } \phi_{m r} \geq \varphi_{m r s}^{*}
$$




$$
=0 \text { if } \varphi_{m r}<\varphi_{m r s}^{*} \text {. }
$$

3.5.5 Selection or Zero-Profit Cutoff. We first solve for zero-profit productivity cutoff for selection into each market in terms of the representative firm productivity. Take $\tilde{\varphi}_{m r}=\varphi_{m r}$ in (3.37) to get

$$
r_{s}\left(\tilde{\varphi}_{m r}\right)=\sigma^{M} c_{m r} f_{m r s}^{M}\left(\frac{\tilde{\varphi}_{m r}}{\varphi_{m r s}^{*}}\right)^{\sigma^{M}-1}
$$

Given the conditional Pareto pdf, we may derive the ratio of the productivity of the representative firm to the zero-profit productivity cutoff. The productivity of our representative firm is:

$$
\tilde{\varphi}_{m r s}=\left[\int_{\varphi_{m r s}^{*}}^{\infty} \varphi_{m r}^{\sigma^{M}-1} \frac{a \varphi_{m r s}^{*} a}{\varphi_{m r}^{a+1}} d \varphi_{m r}\right]^{\frac{1}{\sigma^{M}-1}}=\left[a\left(\varphi_{m r s}^{*}\right)^{a} \int_{\varphi_{m r s}^{*}}^{\infty} \varphi_{m r}^{\sigma^{M}-a-2} d \varphi_{m r}\right]^{\frac{1}{\sigma^{M}-1}}=\left[\frac{a+1-\sigma^{M}}{a}\right]^{\frac{1}{1-\sigma^{M}}}\left(\varphi_{m r s}^{*}\right)
$$

where we assume that $\sigma^{M}-a-1<0$ for the integral to converge. Then, we have

$$
\left(\frac{\tilde{\varphi}_{m r s}}{\varphi_{m r s}^{*}}\right)^{\sigma^{M}-1}=\left[\frac{a+1-\sigma^{M}}{a}\right]^{-1} \text {. }
$$

Substitute (3.48) into (3.47) to yield:

$$
\begin{gathered}
r_{s}\left(\tilde{\varphi}_{m r}\right)=\sigma^{M}{ }_{{ }_{m r}} f_{m r s}^{M}\left[\frac{a+1-\sigma^{M}}{a}\right]^{-1} \text { or } \\
r_{s}\left(\tilde{\varphi}_{m r}\right)\left[\frac{a+1-\sigma^{M}}{a \sigma^{M}}\right]=c_{m r} f_{m r s}^{M}
\end{gathered}
$$

From (3.43), we have that $\tilde{q}_{m r s}=\Upsilon_{m r s} \tilde{p}_{m r s}^{-\sigma^{M}}$; then

$$
\frac{\tilde{p}_{m r s} \tilde{q}_{m r s}}{1+t_{m r s}}=\frac{\Upsilon_{m r s} \tilde{p}_{m r s}^{1-\sigma^{M}}}{1+t_{m r s}}=\tilde{r}_{m r s},
$$

where we used (3.44). So we may replace representative revenue in (3.49) with representative price times quantity over tariff revenue, yielding (3.51). Equation (3.51) is the zero-productivity cutoff condition in terms of the representative firm's profits, which derives equation (2.13) of the equations of the model.

$$
\frac{\tilde{p}_{m r s} \tilde{q}_{m r s}}{1+t_{m r s}}\left[\frac{a+1-\sigma^{M}}{a \sigma^{M}}\right]=c_{m r} f_{m r s}^{M}
$$


3.5.6 Free Entry Equilibrium Condition. We use the various aggregates derived above for the firm's expected profits, revenue, price and quantity. The conditional expected profits for an individual firm in sector $m$ of region $r$ on sales in region $s$ are:

$$
E\left[\pi_{s}\left(\varphi_{m r}\right)\right]=\frac{E\left[r_{s}\left(\varphi_{m r}\right)\right]}{\sigma^{M}}-c_{m r} f_{m r s}^{M}=\frac{\tilde{p}_{m r s} \tilde{q}_{m r s}}{\left(1+t_{m r s}\right) \sigma^{M}}-c_{m r} f_{m r s}^{M} \quad \text { if } \varphi_{m r}>\varphi_{m r s}^{*}
$$

Following Melitz (2003), we assume that these profits are steady-state profits. But there is an annual probability of death of the firm equal to $\delta$ so that $1-\delta$ is the probability of survival. Then, conditional expected profits in the steady state for a potential entrant into sector $m$ of region $r$ on sales to region $s$ are:

$$
\begin{gathered}
\sum_{t=0}^{\infty}(1-\delta)^{t} E\left[\pi_{s}\left(\varphi_{m r}\right)\right]=\frac{E\left[\pi_{s}\left(\varphi_{m r}\right)\right]}{\delta}=\left[\frac{\tilde{p}_{m r s} \tilde{q}_{m r s}}{\left(1+t_{m r s}\right) \sigma^{M}}-c_{m r} f_{m r s}^{M}\right] \frac{1}{\delta} \text { if } \varphi_{m r}>\varphi_{m r s}^{*} \\
=0 \quad \text { if } \varphi_{m r} \leq \varphi_{m r s}^{*} .
\end{gathered}
$$

A potential entrant will realize these profits with probability $\left(1-G\left(\varphi_{m r s}^{*}\right)\right)$. The free entry equilibrium condition is that the expected profits of a potential entrant summed over all markets just equals the sunk costs of entering the market:

$$
\sum_{s \in R}\left[1-G\left(\varphi_{m r s}^{*}\right)\right]\left[\frac{\tilde{p}_{m r s} \tilde{q}_{m r s}}{\left(1+t_{m r s}\right) \sigma^{M}}-c_{m r} f_{m r s}^{M}\right]=\delta c_{m r} f_{m r}^{E}
$$

Since in the steady state equilibrium $\left[1-G\left(\varphi_{m r s}^{*}\right)\right]$ is equal to the share of entering firms in sector $m$ of region $r$ that are active in market $s$, we have:

$$
\left[1-G\left(\varphi_{m r s}^{*}\right)\right]=\frac{N_{m r s}}{n_{m r}}
$$

Then we rewrite (3.54) as:

$$
\sum_{s \in R}\left(\frac{N_{m r s}}{n_{m r}}\right)\left[\frac{\tilde{p}_{m r s} \tilde{q}_{m r s}}{\left(1+t_{m r s}\right) \sigma^{M}}-c_{m r} f_{m r s}^{M}\right]=\delta c_{m r} f_{m r}^{E}
$$

From (3.51), substitute $\frac{\tilde{p}_{m r s} \tilde{q}_{m r s}}{1+t_{m r s}}\left[\frac{a+1-\sigma^{M}}{a \sigma^{M}}\right]$ for $c_{m r} f_{m r s}^{M}$ into (3.55) and simplify. This gives us equation (2.14), the free entry condition of the equations of the model:

$$
\sum_{s \in R}\left(\frac{N_{m r s}}{n_{m r}}\right)\left[\frac{\tilde{p}_{m r s} \tilde{q}_{m r s}\left(\sigma^{M}-1\right)}{\left(1+t_{m r s}\right) a \sigma^{M}}\right]=\delta c_{m r} f_{m r}^{E}
$$


3.5.7 Representative Firm Productivity Level. The Pareto cumulative distribution function is:

$$
G(y)=1-\left(\frac{b}{y}\right)^{a} y \geq b>0 \text {. The probability that the firm's productivity is greater than or }
$$

equal to $\varphi_{m r s}^{*}$ is $\left(\frac{b}{\varphi_{m r s}^{*}}\right)^{a}$, which in equilibrium equals the share of entering firms that are able to be active in market $s$. Thus, we may solve for $\varphi_{m r s}^{*}$ from

$$
\left(\frac{b}{\varphi_{m r s}^{*}}\right)^{a}=\frac{N_{m r s}}{n_{m r}} \text { yielding } b\left(\frac{N_{m r s}}{n_{m r}}\right)^{-1 / a}=\varphi_{m r s}^{*}
$$

Using (3.48), and substituting from (3.57) for $\varphi_{m r s}^{*}$ we have:

$$
\tilde{\varphi}_{m r s}=\left[\frac{a+1-\sigma^{M}}{a}\right]^{1 /\left(1-\sigma^{M}\right)} b\left(\frac{N_{m r s}}{n_{m r}}\right)^{-1 / a}
$$

This is equation (2.15) of the equations of the model.

\subsubsection{Preference Weights in the Dixit-Stiglitz Price Equation of the Melitz Model. We} may relate the preference weights in (2.7), the Dixit-Stiglitz price index of the model, to value shares of absorption in the benchmark data. In the Melitz case, the calibrated share formula for the Dixit-Stiglitz price index is:

$$
P_{m s}=\left[\sum_{r \in R} v_{m r s} \frac{N_{m r s} \tilde{p}_{m r s}^{1-\sigma^{M}}}{N_{m r s}^{0}\left(\tilde{p}_{m r s}^{0}\right)^{1-\sigma^{M}}}\right]^{1 /\left(1-\sigma^{M}\right)}
$$

where the superscript 0 denotes the value of the variable in the benchmark equilibrium and the value shares $v_{m r s}$ are defined in (3.9) where we substitute the subscript $m$ for $i$. We take $N_{m r s}^{0}=1$ and define

$$
\lambda_{m r s}^{M}=v_{m r s}\left(\tilde{p}_{m r s}^{o}\right)^{\sigma^{M}-1}=v_{m r s}\left[\frac{\left(1+t_{m r s}^{0}\right) \tau_{m r s}^{0} c_{m r}^{0}}{\tilde{\varphi}_{m r s}\left(1-1 / \sigma^{M}\right)}\right]^{\sigma^{M}-1}
$$

Substitute $\lambda_{m r s}^{M}$ into (3.59) and we obtain equation (2.7). 


\subsection{Market Clearance Conditions.}

3.6.1 Supply and Demand Balance for Domestic Use. The total quantity supplied of good or service $i$ in region $r$ from all regions is $q 0_{i r} Q_{i r}$. In equilibrium, this must equal the sum of consumer and intermediate demand. Since we have linear homogeneous demand functions for both final and intermediate demand, the compensated demand function for final goods is obtained by applying Shepard's Lemma to the unit expenditure function and multiplying by total final demand in the economy. This gives us the first term on the right-hand side of (3.60). For demand for good $i$ as an input in sector $j$ of region $r$, we apply Shepard's Lemma to the unit cost function for inputs in sector $j$ and multiply by total demand for intermediates in sector $j$. Sum over all sectors $j$ to arrive at second term on the righthand side of (3.60). The market clearance conditions of supply and demand are given by:

$$
q 0_{i r} Q_{i r}=d 0_{r} D_{r} \frac{\partial e_{r}}{\partial P_{i r}}+\sum_{j \in I} y 0_{j r} Y_{j r} \frac{\partial c_{j r}}{\partial P_{i r}} \quad i \in I, r \in R .
$$

In (3.60), the price depends on the market structure of the sector. The price index $P_{i r}$ is defined by (2.5), (2.6) or (2.7), depending on whether the market structure is either Armington, Krugman or Melitz, respectively.

3.6.2 Market Clearance of Good $\boldsymbol{i}$ in Region $\boldsymbol{r}$ in all uses for Armington Goods. Under Armington, the unit cost of good $i$ in region $s$ is given by (3.7):

$$
P_{i s}=\left[\sum_{r \in R} \lambda_{i r s}^{A}\left[\left(1+t_{i r s}\right) \tau_{i r s} c_{i r}\right]^{1-\sigma^{A}}\right]^{1 /\left(1-\sigma^{A}\right)} \quad i \in I, s \in R
$$

and the associated price of good $i$ from region $r$ in region $s$ is $\left(1+t_{i r s}\right) \tau_{i r s} c_{i r}$. Applying Shephard's Lemma to the unit cost function and scaling by total demand for good $i$ in region $s$, gives us total demand for good $i$ from region $r$ in region $s$ :

$$
\sum_{s \in R} q 0_{i s} Q_{i s} \frac{\partial P_{i s}}{\partial\left[\left(1+t_{i r s}\right) \tau_{i r s} c_{i r}\right]}
$$

Firms in region $r$, must ship $\tau_{i r s}$ units of good $i$ to region $s$ for one unit of good $i$ to arrive in region $s$. Incorporating the additional output required to cover the iceberg costs and differentiating (3.7) gives us our market clearance condition for Armington goods:

$$
y 0_{i r} Y_{i r}=\sum_{s \in R} \tau_{i r s} q 0_{i s} Q_{i s} \frac{\partial P_{i s}}{\partial\left[\left(1+t_{i r s}\right) \tau_{i r s} c_{i r}\right]} \quad i \in I, r \in R,
$$


3.6.3 Market Clearance of Good $k$ in Region $r$ in all uses for Krugman Goods. For the monopolistic competition models, we must account for the use of the composite input for both variable and fixed costs. Given the cost function in (3.11), use of the composite input by Krugman firms for its variable costs for its sales to all markets is equal to $\sum_{s \in R} \tau_{k r s} q_{k r s}$. Krugman firms also incur a fixed cost of operating which is also defined in units of the composite input. Then $f_{k r}^{K}+\sum_{s \in R} \tau_{k r s} q_{k r s}$ is the total use of the composite input by a single firm in sector $k$ of region $r$. Supply and demand balance for the total use of the composite input in a Krugman sector in region $r$ is:

$$
y 0_{k r} Y_{k r}=n_{k r}\left(f_{k r}^{K}+\sum_{s \in R} \tau_{k r s} q_{k r s}\right) \quad k \in K, r \in R ;
$$

3.6.4 Market Clearance of Good $\boldsymbol{m}$ in Region $\boldsymbol{r}$ in all uses for Melitz Goods. We first want to find the amount of the composite input required for variable costs to produce the output of all firms in sector $m$ or region $r$ on their sales in region $s$. We use the notation developed above:

$q_{s}\left(\varphi_{m r}\right)=\Upsilon_{m r s} p_{s}\left(\varphi_{m r}\right)^{-\sigma^{M}}=\Upsilon_{m r s} k_{m r s}^{-\sigma^{M}} \varphi_{m r}^{\sigma^{M}}$

where $\Upsilon_{m r s}=\lambda_{m r s}^{M} q 0_{m s} Q_{m s} P_{m s}{ }^{\sigma^{M}}$ and $k_{m r s}=\frac{\left(1+t_{m r s}\right) \tau_{m r s} c_{m r}}{\left(1-1 / \sigma^{M}\right)}$

$\frac{\tau_{m r s} q_{s}\left(\varphi_{m r}\right)}{\varphi_{m r}}$ is the amount of the composite input required for variable costs by a firm in sector $m$ of

region $r$ with productivity $\varphi_{m r}$ for their sales in region $s$. Aggregating over all firms in sector $m$ of region $r$ on their sales in region $s$, we get:

$$
\begin{aligned}
& N_{m r s} E\left[\frac{\tau_{m r s} q_{s}\left(\varphi_{m r}\right)}{\varphi_{m r}}\right]=N_{m r s} \tau_{m r s} \Upsilon_{m r s} k_{m r s}^{-\sigma^{M}} \int_{\varphi_{m r s}^{*}}^{\infty} \frac{\varphi_{m r}^{\sigma^{M}}}{\varphi_{m r}} \frac{g\left(\varphi_{m r}\right)}{1-G\left(\varphi_{m r s}^{*}\right)} d \varphi_{m r} \\
& =N_{m r s} \tau_{m r s} \Upsilon_{m r s} k_{m r s}^{-\sigma^{M}} \tilde{\varphi}_{m r}^{\sigma^{M}-1}=N_{m r s} \tau_{m r s} \Upsilon_{m r s} p_{s}\left(\tilde{\varphi}_{m r}\right)^{-\sigma^{M}} \frac{1}{\tilde{\varphi}_{m r s}} \\
& =N_{m r s} \frac{\tau_{m r s} q_{s}\left(\tilde{\varphi}_{m r}\right)}{\tilde{\varphi}_{m r}}
\end{aligned}
$$

In addition, we must account for the use of the composite input to cover the fixed costs of operation and sunk entry costs. Summing over all markets, gives us the Melitz market clearance condition: 


$$
y 0_{m r} Y_{m r}=\delta f_{m r}^{E} n_{m r}+\sum_{s \in R} N_{m r s}\left(f_{m r s}^{M}+\frac{\tau_{m r s} \tilde{q}_{m r s}}{\tilde{\varphi}_{m r s}}\right) \quad m \in M, r \in R .
$$

3.6.5 Market Clearance for sector-specific primary factors. The demand for a sector-specific factor of production $f$ used in sector $i$ of region $r$ is obtained by applying Shephard's Lemma to the unit cost function of sector $i$ of region $r$. The unit cost function is defined by either (3.3) or (3.5). Given the linear homogeneous demand function, we scale the demand based on one unit of output by total output to obtain the total demand for the specific factor.

$$
\overline{S F}_{f i r}=y 0_{i r} Y_{i r} \frac{\partial c_{j r}}{\partial \tilde{w}_{f i r}} \quad f \in \tilde{F}, i \in I, r \in R .
$$

For primary mobile factors of production, we account for demand across all sectors $i \in I, r \in R$ :

$$
\bar{F}_{f r}=\sum_{i \in I} y 0_{i r} Y_{i r} \frac{\partial c_{j r}}{\partial w_{f r}}+d 0_{r} D_{r} \frac{\partial e_{r}}{\partial w_{f r}} \quad f \in F, f \notin \bar{F}, r \in R .
$$

Leisure demand is given by the final term on the right-hand side, which is non-zero only if the factor is labor and we have chosen a non-zero elasticity of labor supply.

\subsection{Income balance and numeraire}

The model is based on relative prices (the model is homogeneous of degree zero in nominal

prices). We define the numeraire as the price of a unit of utility in the United States, i.e., $e_{U S A} \equiv 1$. All prices are relative to this numeraire.

In terms of units of the numeraire, we must have nominal income equal expenditures of the representative agent in region $r$. Income equals the value of factor endowments plus any tariff revenue plus the value of any capital account surplus in the benchmark equilibrium, where we hold the capital account surplus constant in any counterfactual.

$$
\begin{aligned}
\boldsymbol{I}_{r} & =\sum_{f \notin \tilde{F}} w_{f r} \bar{F}_{f r}+\sum_{f \in \tilde{F}} \sum_{i} \tilde{w}_{f r} \overline{S F}_{f i r}+\sum_{i \notin K \cup M} \sum_{s \in R} t_{i s r} c_{i s} \tau_{m r s} q 0_{i r} Q_{i r} \frac{\partial P_{i r}}{\partial\left[\left(1+t_{i s r}\right) \tau_{i s r} c_{i s}\right]} \\
& +\sum_{k \in K} \sum_{s \in R} t_{k s r} n_{k s} p_{k s r} q_{k s r} /\left(1+t_{k s r}\right)+\sum_{m \in M} \sum_{s \in R} t_{m s r} N_{m s r} \tilde{p}_{m s r} \tilde{q}_{m s r} /\left(1+t_{m s r}\right)+e_{\mathrm{usa}} \overline{B O P_{r}}
\end{aligned}
$$

The first two terms on the right-hand side of (3.67) are the values of mobile factor endowments and sector-specific factor endowments, respectively. With no labor-leisure choice, the initial total labor supply is the endowment. With labor-leisure choice, the endowment of the representative agent is the total time endowment; then income is "full" income, as it includes the imputed value of leisure. The third term 
is the value of tariff revenue collected in all Armington sectors. The quantity demanded in region $r$ of imports of good or service $i$ from region $s$ is: $q 0_{i r} Q_{i r} \frac{\partial P_{i r}}{\partial\left[\left(1+t_{i s r}\right) \tau_{i s r} c_{i s}\right]}$. For each unit of good $i$ from region $s$ that arrives in region $r$, exporters charge for the melt, which is $\tau_{i s r} \geq 1$ units for each unit that arrives. The tariff in region $r$ is assessed on the value $c_{i s} \tau_{m r s}$ per unit.

The fourth term is tariff revenue collected in Krugman sectors. The customs value of imports

from all Krugman firms in sector $k$ of region $s$ into region $r$ equals $n_{k s} p_{k s r} q_{k s r} /\left(1+t_{k s r}\right)$. We then apply the tariff rate on these imports and aggregate over all regions and Krugman sectors.

The fifth term is tariff revenue collected in Melitz sectors. Using equations (3.44), (3.45) and (3.50), the customs value of imports from all Melitz firms in sector $m$ of region $s$ into region $r$ equals:

$$
N_{m s r} E\left[\frac{p_{r}\left(\varphi_{m s}\right) q_{r}\left(\varphi_{m s}\right)}{1+t_{m s r}}\right]=N_{m s r} r_{r}\left(\tilde{\varphi}_{m s r}\right)=N_{m s r} \frac{\tilde{p}_{m s r} \tilde{q}_{m s r}}{1+t_{m s r}}
$$

To obtain the fifth term in (3.67), we apply the tariff rate to the value in (3.68) and sum over all Melitz sectors and regions.

The final term allows for non-zero trade balances based on the data. A trade deficit augments the income available to the representative agent to spend on goods and services. We hold the trade deficit constant in any counterfactual to avoid providing a permanent free lunch that would distort the welfare analysis.

\subsection{Hicksian Equivalent Variation and its Equivalence to the Change in Real Income}

The real income of the consumer equals the quantity associated with full consumption, giving us

$$
d 0_{r} D_{r}=\frac{\boldsymbol{I}_{r}}{e_{r}} \quad r \in R .
$$

where $e_{r}$ was defined in section 2.1.2 as the minimum expenditure required to obtain one unit of utility. We derive Hicksian equivalent variation and show that, in our model, it is equivalent to the change in real income.

3.8.1 No Labor-Leisure Choice Case. We first derive Hicksian equivalent variation in the case of no labor-leisure demand. We have that utility in region $r$ is given by:

$$
d 0_{r} * D_{r}=\frac{1}{\theta_{r}} \prod_{i \in I} C_{i r}^{\theta_{i r}} \quad \text { with } \sum_{i \in I} \theta_{i r}=1 ; \quad \theta_{i r}>0 \quad \text { and } \theta_{r}=\prod_{i \in I} \theta_{i r}^{\theta_{i r}} \quad r \in R .
$$


Here the $C_{i r}$ are homothetic sub-utility functions (CES functions in our case) with price indices $P_{i r}$ dual to the sub-utility functions. This allows two-stage budgeting, where at the top level the consumer decides how much to spend on each aggregate good $C_{i r}$, then optimizes expenditures on each aggregate good $C_{i r}$ subject to the income allocated to expenditure on the aggregate good. This allows us to conduct welfare analysis at the top level. To achieve consistency with the form of our expenditure function, we take a monotonic increasing transformation of the standard Cobb-Douglas utility function.

Maximization of $d 0_{r}^{*} D_{r}$ subject to the income constraint $\boldsymbol{I}_{r}=\sum_{i \in I} P_{i r} C_{i r} \quad$ yields the optimum consumption values:

$$
C_{i r}^{*}=\frac{\theta_{i r} \boldsymbol{I}_{r}}{P_{i r}} \quad \forall i \in I \text { and } r \in R
$$

Define $P_{r}$ as:

$$
P_{r}=\prod_{i \in I} P_{i r}^{\theta_{i r}}
$$

Indirect utility in region $r$ is:

$$
V_{r}\left(\mathrm{P}_{r}, \boldsymbol{I}_{r}\right)=\frac{1}{\theta_{r}} \prod_{i \in I}\left[\frac{\theta_{i r} \boldsymbol{I}_{r}}{P_{i r}}\right]^{\theta_{i}}=\frac{\boldsymbol{I}_{r}}{\prod_{i \in I} P_{i r}^{\theta_{i r}}}=\frac{\boldsymbol{I}_{r}}{P_{r}}
$$

Denote $E_{r}\left[P_{r}, V\left(P_{r}, \boldsymbol{I}_{r}\right)\right]$ as the expenditure function. Given that the expenditure function is the minimum expenditure necessary to reach utility level $V_{r}\left(\mathrm{P}_{r}, \boldsymbol{I}_{r}\right)$, i.e., $\boldsymbol{E}_{r}\left[P_{r}, V\left(P_{r}, \boldsymbol{I}_{r}\right)\right]=\boldsymbol{I}_{r}$, substitute into (3.73) to get:

$$
V_{r}\left(P_{r}, \boldsymbol{I}_{r}\right)=\frac{\boldsymbol{E}_{r}\left[P_{r}, V_{r}\left(P_{r}, \boldsymbol{I}_{r}\right)\right]}{P_{r}}
$$

Setting indirect utility equal to 1 , we see from (3.74) that $P_{r}$ is the minimum expenditure necessary to get one unit of utility, and $e_{r}$ serves as our price index:

$$
P_{r}=E_{r}\left(P_{r}, 1\right)=e_{r} .
$$

Substitute $e_{r}$ for $P_{r}$ in (3.73) to yield equation (2.22)

$$
\frac{\boldsymbol{I}_{r}}{e_{r}}=V_{r}\left(\mathrm{P}_{r}, \boldsymbol{I}_{r}\right)
$$


In region $r$, define $\boldsymbol{\Gamma}_{r}^{0}$ and $\boldsymbol{I}_{r}^{1}$ as income in the benchmark and counterfactual equilibria, respectively; $e_{r}^{t}=P_{r}^{t}=\prod_{i \in I} P_{i r}^{\theta_{i}}(t)$ and $V_{r}\left(P_{r}^{t}, \boldsymbol{I}_{r}^{t}\right)=\frac{\boldsymbol{I}_{r}^{t}}{e_{r}^{t}} t=0,1$ where 0 and 1 denote the benchmark and counterfactual equilibria, respectively. From (3.74), we have that

$$
\boldsymbol{E}_{r}\left[P_{r}, V_{r}\left(P_{r}, \boldsymbol{I}_{r}\right)\right]=P_{r} * V_{r}\left(P_{r}, \boldsymbol{I}_{r}\right)_{r}=P_{r} * \frac{\boldsymbol{I}_{r}}{e_{r}}
$$

Then Hicksian equivalent variation is:

$E V_{r}=E_{r}\left[P_{r}^{0}, V_{r}\left(P_{r}^{1}, \boldsymbol{I}_{r}^{1}\right)\right]-\boldsymbol{E}_{r}\left[P_{r}^{0}, V_{r}\left(P_{r}^{0}, \boldsymbol{I}_{r}^{0}\right)\right]=P_{r}^{0}\left[\frac{\boldsymbol{I}_{r}^{1}}{P^{1}}\right]-P_{r}^{0}\left[\frac{\boldsymbol{I}_{r}^{0}}{P^{0}}\right]=\frac{P_{r}^{0}}{P_{r}^{1}} \boldsymbol{I}_{r}^{1}-\boldsymbol{I}_{r}^{0}$

We want to show that the change in real income is equal to EV. Real income is $\frac{\boldsymbol{I}_{r}}{P_{r}}$. The change in real income is:

$$
\Delta\left[\frac{\boldsymbol{I}_{r}}{P_{r}}\right]=\frac{\boldsymbol{I}_{r}^{1}}{P_{r}^{1}}-\frac{\boldsymbol{I}_{r}^{0}}{P_{r}^{0}}
$$

Multiply $E V_{r}$ by $\frac{1}{P_{r}^{0}}$. We have

$$
\begin{aligned}
& \qquad \frac{E V_{r}}{P_{r}^{0}}=\frac{1}{P_{r}^{0}}\left[\frac{P_{r}^{0}}{P_{r}^{1}} \boldsymbol{I}_{r}^{1}-\boldsymbol{I}_{r}^{0}\right]=\frac{\boldsymbol{I}_{r}^{1}}{P_{r}^{1}}-\frac{\boldsymbol{I}_{r}^{0}}{P_{r}^{0}}=\Delta \frac{\boldsymbol{I}_{r}}{P_{r}} \\
& \text { i.e., } \quad E V_{r}=P_{r}^{0} *\left[\Delta \frac{\boldsymbol{I}_{r}}{P_{r}}\right]=e_{r}^{0} *\left[\Delta \frac{\boldsymbol{I}_{r}}{e_{r}}\right] \quad \forall r \in R
\end{aligned}
$$

In general, we choose units such that prices are unity in the benchmark. If all prices are one in the initial equilibrium, the initial price indices $P_{r}^{0}$ are unity, and we have that EV equals the change in real income. However, given the presence of tariffs, not all prices can be equal to one. The MPSGE software, however, does an additional scaling of units, so that the price indices $P_{r}^{0}$ are unity in the benchmark.

With this scaling, the change in real income equals Hicksian equivalent variation.

3.8.2 Extension to Labor-Leisure Choice. To incorporate labor-leisure choice, we need to define the following notation:

$w_{L}=$ the wage rate of labor (this variable is $w_{f r}$ for $f=L$ in the equations of the model);

$l$ and $L$ as the time devoted to leisure and work, respectively;

$E N=$ the total time endowment of the consumer-worker; 
$I_{N L}=$ non-labor income of the consumer-worker.

We define the composite commodity in region $r$ as $C_{r}=\frac{1}{\theta} \prod_{i \in I} C_{i r}^{\theta_{i r}}$ and substitute it into (3.2) yielding:

$$
d 0_{r} * D_{r}=\left[\mu_{r}^{\frac{1}{\sigma^{L}}} l_{r}^{\frac{\sigma^{L}-1}{\sigma^{L}}}+\left(1-\mu_{r}\right)^{\frac{1}{\sigma^{L}}}\left(C_{r}\right)^{\frac{\sigma^{L}-1}{\sigma^{L}}}\right]^{\frac{\sigma^{L}}{\sigma^{L}-1}} \quad r \in R
$$

Since this derivation applies for all regions $r$, to simplify notation we suppress the region subscript $r$ in this subsection. Since $C$ is homothetic and has the dual price $P=\prod_{i \in I} P_{i}^{\theta_{i}}$ defined in (3.72), we may employ two-stage budgeting once again to determine the demand for leisure and the composite commodity $C$.

We have that $E N=l+L$ and $w_{L} L+I_{N L}=P C$. Taking the imputed value of time as part of "full income," we define full income as: $\boldsymbol{I}=w_{L} l+P C$. We maximize (3.81) with respect to $l$ and $C$ subject to "expenditure" on leisure and commodities being equal to full income $\boldsymbol{I}=w_{L} l+P C$. This is the usual CES optimization, yielding

$$
l=\mu\left(\frac{P_{f}}{w_{L}}\right)^{\sigma} \frac{\boldsymbol{I}}{P_{f}} \quad \text { and } C=(1-\mu)\left(\frac{P_{f}}{P}\right)^{\sigma} \frac{\boldsymbol{I}}{P_{f}}
$$


where $P_{f}=\left(\mu w_{L}{ }^{1-\sigma}+(1-\mu) P^{1-\sigma}\right)^{\frac{1}{1-\sigma}}=\left(\mu w_{L}^{1-\sigma}+(1-\mu)\left(\prod_{i \in I} P_{i}^{\theta_{i}}\right)^{1-\sigma}\right)^{\frac{1}{1-\sigma}}$ is the

minimum cost of a unit of utility when there is a labor-leisure choice, where we use (3.72) to substitute for $P$. Substitute the optimal values of $l$ and $C$ into (3.81), yielding indirect utility ${ }^{12}$ :

$$
V\left(P_{f}, \boldsymbol{I}\right)=\frac{\boldsymbol{I}}{P_{f}}=d 0 * D
$$

Using the property of the expenditure function that: $E\left[P_{f}, V\left(P_{f}, \boldsymbol{I}\right)\right]=\boldsymbol{I}$, with labor-leisure choice the expenditure function is:

$$
\boldsymbol{E}\left[P_{f}, V\left(P_{f}, \boldsymbol{I}\right)\right]=V\left(P_{f}, \boldsymbol{I}\right)^{*} P_{f}=\frac{\boldsymbol{I}}{P_{f}} P_{f} .
$$

Choose $V=1$; we obtain that our unit expenditure function is our price index $E_{r}\left[P_{f}, 1\right]=e_{r}=P_{f r}$ and

$$
e_{r}=\left[\mu_{r} w_{L r}^{1-\sigma^{L}}+\left(1-\mu_{r}\right)\left(\prod_{i \in I} P_{i r}^{\theta_{i r}}\right)^{1-\sigma^{L}}\right]^{1 /\left(1-\sigma^{L}\right)} \quad r \in R
$$

which is the unit expenditure function (2.1) of the model. Substitute $P_{f}$ for $P$ in (3.78) and (3.79). We have:

$$
E V=\frac{P_{f}^{0}}{P_{f}^{1}} \boldsymbol{I}^{1}-\boldsymbol{I}^{0} \text { and }
$$

$$
\begin{aligned}
& \left.V\left(P_{f}, \boldsymbol{I}\right)=[\mu)^{\frac{1}{\sigma^{L}}}\left(\mu\left(\frac{P_{f}}{w_{L}}\right)^{\sigma^{L}} \frac{\boldsymbol{I}}{P_{f}}\right)^{\frac{\sigma^{L}-1}{\sigma^{L}}}+(1-\mu)^{\frac{1}{\sigma^{L}}}\left((1-\mu)\left(\frac{P_{f}}{P}\right)^{\sigma^{L}} \frac{\boldsymbol{I}}{P_{f}}\right)^{\frac{\sigma^{L}-1}{\sigma^{L}}}\right]^{\frac{\sigma^{L}}{\sigma^{L}-1}} \\
& =\frac{\boldsymbol{I}}{P_{f}}\left[\mu\left(\left(\frac{P_{f}}{w_{L}}\right)^{\sigma^{L}}\right)^{\frac{\sigma^{L}-1}{\sigma^{L}}}+(1-\mu)\left(\left(\frac{P_{f}}{P}\right)^{\sigma^{L}}\right)^{\frac{\sigma^{L}-1}{\sigma^{L}}}=\frac{\boldsymbol{I} P_{f}^{\sigma^{L}}}{P_{f}}\left[\mu w_{L}^{1-\sigma^{L}}+(1-\mu) P^{1-\sigma^{L}}\right]^{\frac{\sigma^{L}}{\sigma^{L}-1}}=\frac{\boldsymbol{I} P_{f}^{\sigma^{L}}}{P_{f}} P_{f}^{-\sigma^{L}}=\frac{\boldsymbol{I}}{P_{f}}\right.
\end{aligned}
$$




$$
\Delta\left[\frac{\boldsymbol{I}}{P_{f}}\right]=\frac{\boldsymbol{I}^{1}}{P_{f}^{1}}-\frac{\boldsymbol{I}^{0}}{P_{f}^{0}} .
$$

With the regional identifiers and using (3.85), we have:

$$
E V_{r}=P_{f r}^{0} *\left[\Delta \frac{\boldsymbol{I}_{r}}{P_{f r}}\right]=e_{f r}^{0} *\left[\Delta \frac{\boldsymbol{I}_{r}}{e_{f r}}\right] \quad r \in R .
$$

We scale units of goods, services and labor, such that the initial prices and wage rate yield $P_{f r}^{0}=1$. With this scaling of prices, we have equivalence of Hicksian equivalent variation and the change in real income with labor-leisure choice for each region.

\section{Market Productivity Cutoffs: Impact of Market Size and Preferences}

For firms in any region $r$ of our model, we derive the condition for the ratio of the zero cutoff productivity in any of its export markets $s$ to the zero-productivity cutoff condition in its home market:

$\frac{\varphi_{m r s}^{*}}{\varphi_{m r r}^{*}}$. We show that additional fixed costs of exporting, iceberg costs and tariffs all lead to a higher zeroproductivity cutoff for exporting than for sales in the home market. That is, these considerations lead to the Melitz result that exporting firms are a proper subset of firms that sell in the home market and support the stylized fact that exporting firms are a minority of total firms in any region. But with heterogeneous regions, we could find that some firms find it profitable to export to some markets without serving the home market. This could happen if there are large export markets relative to the home market or relatively weak home market preferences for the product of a sector. Feenstra (2010, equation 19) derives a similar condition for a one-sector model with two heterogeneous regions. We extend the result to an arbitrary finite number of sectors and regions.

From (3.36), we have: $r_{s}\left(\varphi_{m r s}^{*}\right)=\sigma^{M} c_{m r} f_{m r s}^{M}$. Then, the ratio of the revenues at the zero profit cutoffs is:

$$
\frac{r_{s}\left(\varphi_{m r s}^{*}\right)}{r_{r}\left(\varphi_{m r r}^{*}\right)}=\frac{f_{m r s}^{M}}{f_{m r r}^{M}}
$$

Equation (3.34) holds for all $s \in R$. Choose $r=s$ as the destination region in (3.34) and substitute $\varphi_{m r s}^{*}$ for $\varphi_{m r}^{\prime \prime}$ and $\varphi_{m r r}^{*}$ for $\varphi_{m r}^{\prime}$. We have that: 


$$
\frac{r_{r}\left(\varphi_{m r s}^{*}\right)}{r_{r}\left(\varphi_{m r r}^{*}\right)}=\left(\frac{\varphi_{m r s}^{*}}{\varphi_{m r r}^{*}}\right)^{\sigma^{M}-1}
$$

We want to express $r_{r}\left(\varphi_{m r s}^{*}\right)$ in terms of $r_{s}\left(\varphi_{m r s}^{*}\right)$.

$$
\begin{aligned}
& r_{s}\left(\varphi_{m r}\right)=\frac{\Upsilon_{m r s}}{1+t_{m r s}} p_{s}\left(\varphi_{m r}\right)^{1-\sigma^{M}}=\frac{\Upsilon_{m r s}}{1+t_{m r s}}\left[\left(1+t_{m r s}\right) \tau_{m r s} p_{r}\left(\varphi_{m r}\right)\right]^{1-\sigma^{M}} \\
& =\frac{\Upsilon_{m r s}}{\Upsilon_{m r r}}\left[\left(1+t_{m r s}\right) \tau_{m r s}\right]^{1-\sigma^{M}} \frac{\Upsilon_{m r r} p_{r}\left(\varphi_{m r}\right)^{1-\sigma^{M}}}{\left(1+t_{m r s}\right)}=\frac{\Upsilon_{m r s}}{\Upsilon_{m r r}}\left(1+t_{m r s}\right)^{-\sigma^{M}} \tau_{m r s}^{1-\sigma^{M}} r_{r}\left(\varphi_{m r}\right)=h_{m r s} r_{r}\left(\varphi_{m r}\right)
\end{aligned}
$$

Where $h_{m r s}=\frac{\Upsilon_{m r s}}{\Upsilon_{m r r}}\left(1+t_{m r s}\right)^{-\sigma^{M}} \tau_{m r s}^{1-\sigma^{M}}$. Divide both sides by $h_{m r s}$ to obtain:

$$
r_{r}\left(\varphi_{m r}\right)=\frac{r_{s}\left(\varphi_{m r}\right)}{h_{m r s}} \forall \varphi_{m r} \text { and, in particular, } r_{r}\left(\varphi_{m r s}^{*}\right)=\frac{r_{s}\left(\varphi_{m r s}^{*}\right)}{h_{m r s}}
$$

Substitute $\frac{r_{s}\left(\varphi_{m r s}^{*}\right)}{h_{m r s}}$ for $r_{r}\left(\varphi_{m r s}^{*}\right)$ in (4.2) and use (4.1) to get

$$
\frac{r_{s}\left(\varphi_{m r s}^{*}\right)}{r_{r}\left(\varphi_{m r r}^{*}\right)}=\left(\frac{\varphi_{m r s}^{*}}{\varphi_{m r r}^{*}}\right)^{\sigma^{M}-1} h_{m r s}=\frac{f_{m r s}^{M}}{f_{m r r}^{M}}
$$

Rearranging, we have

$$
\left(\frac{\varphi_{m r s}^{*}}{\varphi_{m r r}^{*}}\right)=\left(\frac{f_{m r s}^{M}}{f_{m r r}^{M} h_{m r s}}\right)^{\frac{1}{\sigma^{M}-1}}=\left(\frac{f_{m r s}^{M}}{f_{m r r}^{M}}\right)^{\frac{1}{\sigma^{M}-1}}\left(1+t_{m r s}\right)^{\sigma^{M} /\left(\sigma^{M}-1\right)} \tau_{m r s}\left(\frac{\Upsilon_{m r r}}{\Upsilon_{m r s}}\right)^{\frac{1}{\sigma^{M}-1}}
$$

Typically, there are additional fixed costs of exporting. ${ }^{13}$ Then the additional fixed costs, the iceberg costs and the tariffs all lead to a higher zero-productivity cutoff for exporting; thus, these parameters on the right-hand side of Error! Reference source not found. are consistent with the stylized fact that exporting firms are a significant minority of total firms of a region and exporting firms are larger. On the other hand, anything that contributes to $\frac{\Upsilon_{m r r}}{\Upsilon_{m r s}}$ being less than one could lead to some firms exporting without serving their domestic market.

${ }^{13}$ It is possible, however, that there are cases where fixed costs of exporting to some region are lower than fixed costs of serving the home market. For example, regulatory costs may be higher in the home market. 


$$
\frac{\Upsilon_{m r r}}{\Upsilon_{m r s}}=\frac{\lambda_{m r r}^{M} q 0_{m r} Q_{m r} P_{m r}{ }^{\sigma^{M}}}{\lambda_{m r s}^{M} q 0_{m s} Q_{m s} P_{m s}{ }^{\sigma^{M}}}
$$

Notably, for firms in small home markets, there may be sufficiently large export markets such that the zero-productivity cutoff for exports is lower than the home market zero-productivity cutoff; this would result in some firms exporting without selling in their home market.

\section{References}

Anderson, James E. and Eric van Wincoop (2003), "Gravity with Gravitas: A Solution to the Border Puzzle," American Economic Review, Vol. 93 (1), 170-192.

Armington, Paul (1969), “A Theory of Demand for Products Distinguished by Place of Production,” International Monetary Fund Staff Papers, Vol. 16 (1), 159-178.

Balistreri, Edward J. and Russell Hillberry (2007), "Structural Estimation and the Border Puzzle," Journal of International Economics, Vol. 72 (2), 451-463.

Balistreri, Edward J. and Thomas F. Rutherford (2013), "Computing General Equilibrium Theories of Monopolistic Competition and Heterogeneous Firms," in Handbook of Computable General Equilibrium Modeling, Vol.

1, Peter B. Dixon and Dale W. Jorgenson eds., Amsterdam, North Holland, Elsevier, Chapter 23, 15131570.

Balistreri, Edward J., David G. Tarr (2018), "Comparison of Welfare Gains in the Armington, Krugman and Melitz Models: Insights from a Structural Gravity Model,” World Bank Policy Research Working Paper No. 8570, September. Available at: https://papers.ssrn.com/sol3/papers.cfm?abstract_id=3247295.

Bernard, A.B., J. Eaton, , J.B. Jensen and S. Kortum (2003), "Plants and productivity in international trade," American Economic Review Vol. 93 (4), 1268-1290.

Costinot, Arnaud and Andres Rodriguez-Clare (2013), "Online Appendix to Trade Theory with Numbers: Quantifying the Consequences of Globalization," March. Available at:

https://economics.mit.edu/files/9215 
Craven, B. D. (1970), “A Generalization of Lagrange Multipliers,” Bulletin of the Australian Mathematical Society, Vol. 3, 353-362. Available at: https://www.cambridge.org/core/services/aop-cambridgecore/content/view/S0004972700046050.

Feenstra, Robert (2010), “Measuring the Gains From Trade Under Monopolistic Competition,” Canadian Journal of Economics, Vol. 43 (1), 1-28.

Helpman, Elhanan and Paul Krugman (1985), Market Structure and Foreign Trade, Cambridge, MA: MIT Press.

Krugman, Paul. (1980), "Scale Economies, Product Differentiation, and the Pattern of Trade," The American Economic Review, 70 (5), 950-959.

Markusen, James, Thomas F. Rutherford and David G. Tarr (2005), “Trade and Direct Investment in Producer Services and the Domestic Market for Expertise," Canadian Journal of Economics, Vol. 38 (3), 758-777.

Melitz, Marc J. (2003): “The Impact of Trade on Intra-Industry Reallocations and Aggregate Industry Productivity," Econometrica, Vol. 71 (6), 1695-1725

Rutherford, Thomas F. (2002), "Lecture Notes on Constant Elasticity Functions." Available at: http://www.gamsworld.org/mpsge/debreu/ces.pdf 


\section{Figure 1: Circular Flow: Armington Model for Good $\boldsymbol{i}$ in Region $\boldsymbol{r}$.}

Arrows indicate the physical flows of goods or services in sector $i$ of region $r$. Payments go in the opposite direction.*

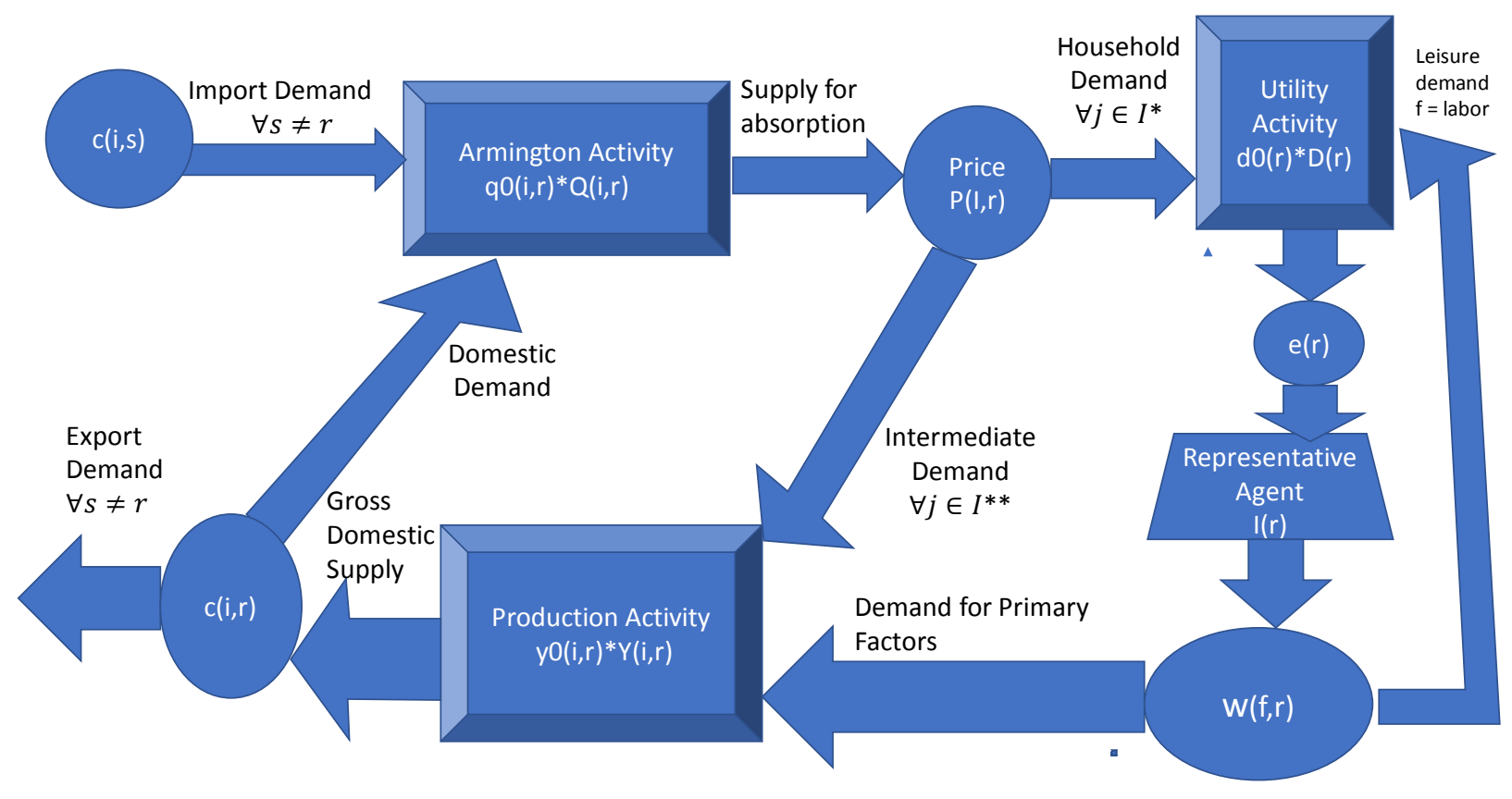

*The utility activity demands goods or services from all the Armington activities $j$ for all $j \in I$.

**The production activity in sector $i$ uses intermediates from all the Armington activities $j$ for all $j \in I$. 